\title{
Arborization of Dendrites by Developing Neocortical Neurons Is Dependent on Primary Cilia and Type 3 Adenylyl Cyclase
}

\author{
Sarah M. Guadiana, ${ }^{1}$ Susan Semple-Rowland, ${ }^{1}$ Daniel Daroszewski, ${ }^{1}$ Irina Madorsky, ${ }^{1}$ Joshua J. Breunig, ${ }^{2}$ \\ Kirk Mykytyn, ${ }^{3}$ and Matthew R. Sarkisian ${ }^{1}$ \\ ${ }^{1}$ Department of Neuroscience, McKnight Brain Institute, University of Florida, Gainesville, Florida 32610-0244, ${ }^{2}$ Cedars-Sinai Regenerative Medicine \\ Institute, Los Angeles, California 90036, and ${ }^{3}$ Department of Pharmacology, Wexner Medical Center, Ohio State University, Columbus, Ohio 43210
}

\begin{abstract}
The formation of primary cilia is a highly choreographed process that can be disrupted in developing neurons by overexpressing neuromodulatory G-protein-coupled receptors GPCRs or by blocking intraflagellar transport. Here, we examined the effects of overexpressing the ciliary GPCRs, 5HT6 and SSTR3, on cilia structure and the differentiation of neocortical neurons. Neuronal overexpression of 5HT6 and SSTR3 was achieved by electroporating mouse embryo cortex in utero with vectors encoding these receptors. We found that overexpression of ciliary GPCRs in cortical neurons, especially 5HT6, induced the formation of long $(>30 \mu \mathrm{m})$ and often forked cilia. These changes were associated with increased levels of intraflagellar transport proteins and accelerated ciliogenesis in neonatal neocortex, the induction of which required Kif3a, an anterograde motor critical for cilia protein trafficking and growth. GPCR overexpression also altered the complement of signaling molecules within the cilia. We found that SSTR3 and type III adenylyl cyclase (ACIII), proteins normally enriched in neuronal cilia, were rarely detected in 5HT6-elongated cilia. Intriguingly, the changes in cilia structure were accompanied by changes in neuronal morphology. Specifically, disruption of normal ciliogenesis in developing neocortical neurons, either by overexpressing cilia GPCRs or a dominant-negative form of Kif3a, significantly impaired dendrite outgrowth. Remarkably, coexpression of ACIII with 5HT6 restored ACIII to cilia, normalized cilia structure, and restored dendrite outgrowth, effects that were not observed in neurons coexpressing ACIII and dominant-negative form of Kif3a. Collectively, our data suggest the formation of neuronal dendrites in developing neocortex requires structurally normal cilia enriched with ACIII.
\end{abstract}

\section{Introduction}

Interest in the biological functions of the primary cilia of cortical neurons and their influence on neuronal maturation and cortical development has dramatically increased in recent years (Louvi and Grove, 2011), in part because several developmental and neurological disorders have now been linked to defects in ciliogenesis (Green and Mykytyn, 2010; Bennouna-Greene et al., 2011; Lee and Gleeson, 2011; Novarino et al., 2011; Sattar and Gleeson, 2011). As a first step toward understanding the impact that primary cilia have on neuron function and maturation, we characterized the time course of neuronal ciliogenesis in developing mouse neocortex (Arellano et al., 2012). Neuronal cilio-

Received June 18, 2012; revised Dec. 6, 2012; accepted Dec. 12, 2012.

Author contributions: S.M.G., K.M., and M.R.S. designed research; S.M.G., S.S.-R., D.D., I.M., J.J.B., K.M., and M.R.S. performed research; S.S.-R., D.D., I.M., J.J.B., and K.M. contributed unpublished reagents/analytic tools; S.M.G., S.S.-R., J.J.B., K.M., and M.R.S. analyzed data; S.M.G., S.S.-R., J.J.B., K.M., and M.R.S. wrote the paper.

This work was supported by the Bryan Robinson Endowment (to S.M.G.) and the McKnight Brain Research Foundation and University of Florida College of Medicine (to M.R.S.). We thank J. Eggenschwiler for the TULP3 antibody, S. Ge for the dnKif3a cDNA construct, and D. Siebzehnrubl and D. Smith in the Cell and Tissue Analysis Core for technical assistance.

The authors declare no competing financial interests.

Correspondence should be addressed to Dr. Matthew R. Sarkisian, Department of Neuroscience, McKnight Brain Institute, University of Florida, Gainesville, FL 32610-0244. E-mail: msarkisian@ufl.edu.

DOI:10.1523/JNEUROSCI.2906-12.2013

Copyright $\odot 2013$ the authors $\quad 0270-6474 / 13 / 332626-13 \$ 15.00 / 0$ genesis progresses through several stages in postmigratory neurons, the first of which is distinguished by the appearance of the "procilium" that is formed as a result of outgrowth of the early-stage ciliary plasma membrane (Arellano et al., 2012). Shortly after birth, the elongation stage begins during which time microtubules within the procilium assemble and organize to form the axoneme that continues to elongate over the first $8-12$ weeks of life. During the procilium and elongation stages of ciliogenesis, the cilia become enriched with signaling enzymes (e.g., type 3 adenylyl cyclase [ACIII]) (Berbari et al., 2007; Bishop et al., 2007; Anastas et al., 2011; Arellano et al., 2012), nerve growth factor receptors (e.g., p75NTR) (Chakravarthy et al., 2010), and specific GPCRs (e.g., 5HT6, SSTR3, MCHR1, and D1) (Handel et al., 1999; Brailov et al., 2000; Miyoshi et al., 2006; Berbari et al., 2008a,b; Stanić et al., 2009; Marley and von Zastrow, 2010) that enable the cilia to respond to ligands in the extracellular environment. The process of intraflagellar transport (IFT) not only promotes neuronal ciliogenesis but also supports the bidirectional trafficking of these ciliary signaling molecules within the cilium.

There is growing evidence that disruption of the formation or function of neural cilia adversely affects neuronal differentiation. For example, in neurons born in the adult hippocampus, blocking the function of Kif3a, an anterograde motor protein that is required for CNS ciliogenesis (Chizhikov et al., 2007; Davenport et al., 2007; Han et al., 2008; Spassky et al., 2008), has been re- 
Table 1. Plasmid CDNA vectors used in this study

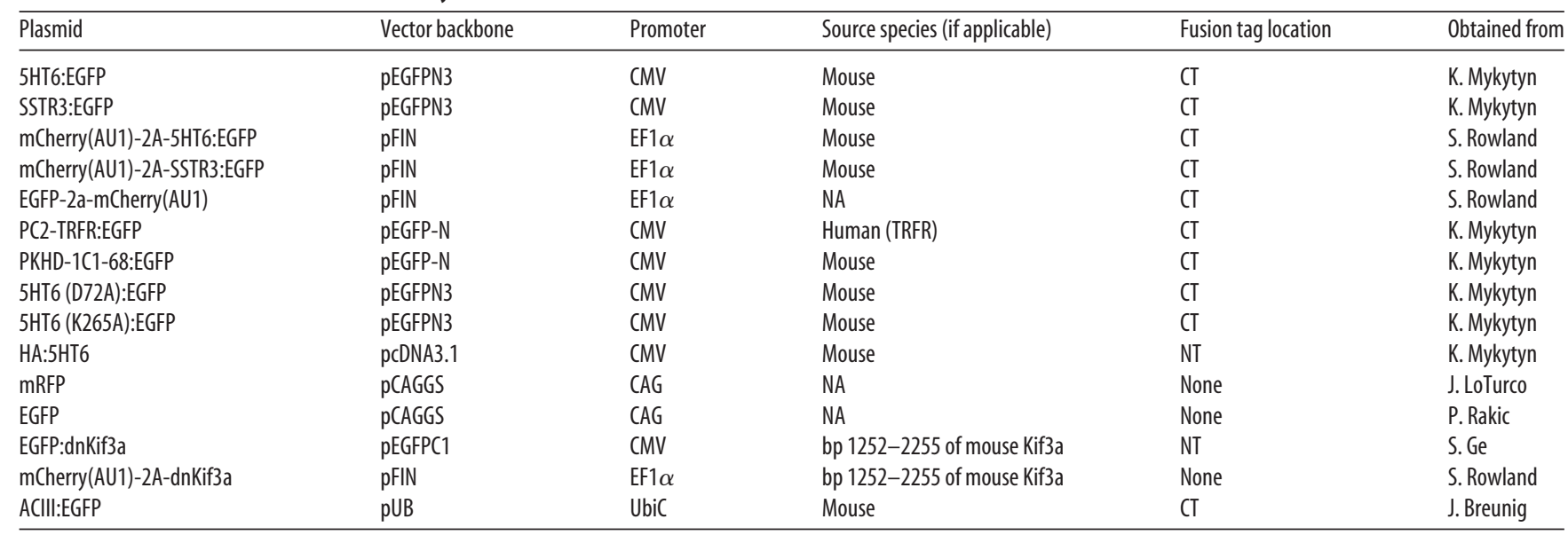

NA, Not applicable.

ported to disrupt dendritic arborization of these neurons and their synaptic integration into the hippocampus (Kumamoto et al., 2012). In addition, overexpression of the double-cortin domain-containing protein 2 in cultured rat hippocampal neurons, a protein that interacts with Kif3a, has been reported to induce cilia elongation and alter the dendritic branching of these neurons (Massinen et al., 2011). These findings raise the question as to whether the growth and differentiation of other cortical neuron subtypes are altered by disruption of their cilia. For example, although targeted ablation of cilia hindered dendritic outgrowth in adult-born hippocampal granule neurons (Kumamoto et al., 2012), ablating cilia in postmigratory cortical interneurons did not significantly alter differentiation (Higginbotham et al., 2012). Given the range of these observations, we wondered whether cilia regulate the differentiation and maturation of projection neurons in developing neocortex.

The purpose of this study was to investigate the relationship between ciliogenesis and the differentiation of neocortical neurons in developing cortex. We hypothesized that disruption of ciliogenesis in developing neocortical neurons would induce abnormal dendritic outgrowth. In this study, we overexpressed neuronal cilia GPCRs in developing neocortical neurons to disrupt ciliogenesis, a strategy that we found induces significant lengthening of primary cilia of immortalized cells. We found that neurons overexpressing cilia GPCRs developed exceedingly long, malformed cilia, and that dendrite outgrowth from these neurons was severely stunted in a manner similar to that observed for neurons lacking cilia. Moreover, our findings suggest that changes in the complement of signaling proteins present in the cilia that were induced by overexpression of the GPCRs contributed to the abnormal dendritic phenotype exhibited by these neurons.

\section{Materials and Methods}

Mice. All animal protocols were approved by and performed in accordance with the Institutional Animal Care and Use Committee at the University of Florida. CD1 mouse brains were collected on embryonic (E) day $14.5(n=9), \mathrm{E} 16.5(n=92)$, postnatal $(\mathrm{P})$ day $1(n=5), \mathrm{P} 10(n=$ $10)$, and P14 $(n=37)$. Postnatal mice of either sex were intracardially perfused with saline followed by $4 \%$ paraformaldehyde in $0.1 \mathrm{M}$ phosphate buffer solution (4\% PFA). All brain tissues were postfixed overnight in $4 \%$ PFA at $4^{\circ} \mathrm{C}$. After fixation, the brains were rinsed, cryoprotected in sucrose, frozen over liquid $\mathrm{N}_{2}$, and sectioned (40-50 $\mu \mathrm{m}$ coronal) using a cryostat.

In utero electroporation. Vectors were delivered to the developing cortices of E15.5 mice using in utero electroporation as previously described
(Sarkisian et al., 2006). Briefly, at 15.5 d into gestation, female mice were anesthetized by intraperitoneal injections of ketamine $(100 \mathrm{mg} / \mathrm{kg})$ and xylazine $(10 \mathrm{mg} / \mathrm{kg})$ diluted in sterile saline. Mice received meloxicam (1 $\mathrm{mg} / \mathrm{kg}$ ) as an analgesic. The uterine horns were exposed, and $\sim 1 \mu \mathrm{l}$ of DNA $(0.5-2 \mu \mathrm{g} / \mu \mathrm{l}$, mixed with $0.025 \%$ Fast-Green) was microinjected through the uterine wall into the cerebral lateral ventricles of the mouse embryos using pulled glass capillaries. Electroporation was achieved by discharging $50 \mathrm{~V}$ across the cortex in 5-pulse series spaced $50 \mathrm{~ms}$ apart (pulse duration $=950 \mathrm{~ms}$ ) using a BTX ECM 830 Square Wave Electroporator. After injections, the dams were sutured and allowed to recover on heating pads.

Vectors. Table 1 describes the vectors used in this study and their promoter/protein tag information if applicable. pEGFP-N3 vectors were constructed that encoded either mouse SSTR3 or mouse 5HT6 that were fused to EGFP on the C termini. The expression of SSTR3:EGFP and 5HT6:EGFP in these vectors was controlled by a human CMV immediate early promoter. Lentiviral vectors were generated that encoded mCherry tagged with AU1 upstream of dominant-negative form of Kif3a (dnKif3a), or either SSTR3 or 5HT6 that were fused to EGFP on the C termini. mCherry(AU1) and dnKif3a, SSTR3:EGFP or 5HT6:EGFP in these vectors were fused to each other using the pTV1 2A cleavage peptide. The expression of all lentiviral transgenes was controlled by an elongation factor $1 \alpha(\mathrm{EF} 1 \alpha)$ promoter (Verrier et al., 2011). Additional 5 HT6 vectors used included pcDNA3.1-HA:5HT6 encoding 5HT6 with a $\mathrm{HA}$ tag fused to the $\mathrm{N}$ terminus, and two signaling defective 5 HT6 receptor constructs 5HT6 (D72A):EGFP and 5HT6 (K265A):EGFP, which have been previously described (Kang et al., 2005; Zhang et al., 2006). The K265A point mutation completely abolishes the signaling capabilities of the 5HT6 receptor and reduces cAMP levels to $5 \%$ of those found in wild-type cells. The D72A point mutation reduces the binding affinity of the $5 \mathrm{HT} 6$ receptor for $5 \mathrm{HT}$ and reduces downstream activation of adenylyl cyclase III by $60 \%$. The PKHD-1C1- 68 vector encodes 68 amino acids immediately downstream of the transmembrane domain of fibrocystin, the human autosomal recessive polycystic kidney disease protein. These 68 amino acids, which include the 18 residues near the $\mathrm{N}$ terminus that contains the cilia targeting sequence, were fused to the $\mathrm{N}$ terminus of EGFP (Follit et al., 2010). The PC2-TRFN vector encodes the cilia targeting sequence of polycystin-2 (PC2) (Geng et al., 2006) fused to the first 61 amino acids of the $\mathrm{N}$ terminus of the human transferrin receptor, all of which were fused to the $\mathrm{N}$ terminus of EGFP. The human transferrin receptor imports iron into cells and is not normally trafficked to the cilium (Geng et al., 2006; Avasthi et al., 2012). The vector encoding full-length mouse ACIII was fused to the C terminus (ACIII:EGFP) and under control of the ubiquitin-C (UbiC) promoter. All control experiments were performed using pCAGGS-EGFP, pCAGGS-mRFP, or EF1 $\alpha$-EGFP-2A-mCherry expressing vectors.

Cell culture. NIH3T3 cells were seeded onto glass coverslips in DMEM supplemented with $10 \%$ FBS and $1 \times$ antibiotic-antimycotic solution 
(cDMEM, Invitrogen). Cells were seeded into 24-well plates at a density of $3.6 \times 10^{6}$ cells/well and were transfected $24 \mathrm{~h}$ later. The cells were transfected with the indicated cDNAs $(0.8 \mu \mathrm{g} / \mathrm{well})$ using Lipofectamine2000 (Invitrogen) in serum-free DMEM (Mediatech Cellgro \#10-013-CV). After 4-6 h, the transfection media was replaced with cDMEM, and the cells were allowed to grow for $48 \mathrm{~h}$ at $37^{\circ} \mathrm{C}$ in $5 \% \mathrm{CO}_{2}$. After $48 \mathrm{~h}$ of growth, the cells were fixed in $4 \%$ PFA for $15 \mathrm{~min}$ at room temperature and washed $3 \times$ with PBS.

Electroporated mRFP or $\mathrm{EGFP}^{+}$neurons located in the dorsal telencephalon were dissected from the brains of E16.5 mice (6-8 fetal cortices/group) and were placed into ice-cold HBSS containing 25 mM HEPES buffer and $0.5 \%(\mathrm{w} / \mathrm{v})$ glucose. The tissues were transferred into prewarmed Trypsin LE solution (Invitrogen) supplemented with $10 \mathrm{~mm}$ HEPES and were then dissociated by trituration with a fire-polished glass pipette. The dissociated cells were resuspended in Neurobasal medium (Invitrogen) supplemented with $2 \mu \mathrm{M}$ sodium pyruvate, $4 \mu \mathrm{M}$ L-glutamine, $1 \times$ antibiotic-antimycotic liquid (Invitrogen), 5\% FBS, and $2 \%(\mathrm{v} / \mathrm{v}) \mathrm{B} 27$ (Invitrogen) and were seeded at a density of $1.5 \times 10^{5}$ cells/well in 24-well plates containing sterile glass coverslips that had been coated with polyornithine $(0.001 \%)$ and laminin $(5 \mu \mathrm{g} / \mathrm{ml})$. To promote neuron differentiation, $50 \%$ of the culture media was replaced with media lacking serum $24 \mathrm{~h}$ after seeding followed by $50 \%$ of the media being replaced every other day. Throughout the experiment, the cultures were maintained at $37^{\circ} \mathrm{C}$ in $5 \% \mathrm{CO}_{2}$. Neurons were cultured for up to $12 \mathrm{~d}$ in vitro (DIV) and were then fixed in $4 \%$ PFA for $15 \mathrm{~min}$ at room temperature and washed $3 \times$ with PBS.

Immunostaining. Cultured cells or brain cryosections were incubated overnight at $4^{\circ} \mathrm{C}$ with the following primary antibodies: mouse antiacetylated $\alpha$-tubulin (1:2000; Sigma), rabbit antiadenylyl cyclase (ACIII) (1: 10,000; EnCor BioTechnology, 1:1000; Santa Cruz Biotechnology), mouse anti-pericentrin (1:500; BD Biosciences), rabbit anti-IFT88 (1: 500; Covance), chicken anti-GFP (1:5000; Abcam), and goat anti-SSTR3 (1:200; Santa Cruz Biotechnology). Appropriate, species-specific, secondary antibodies conjugated to fluorescent tags were used to visualize the primary antibodies (1:200; Jackson ImmunoResearch Laboratories). Immunostained sections were coverslipped using ProLong Gold Antifade media containing DAPI (Invitrogen).

Analyses and quantification of cilia. Immunostained cell cultures and brain sections were examined using an Olympus IX81-DSU spinning disc confocal microscope. Z-stack images (0.5-0.75 $\mu \mathrm{m}$ per step) of ACIII, acetylated $\alpha$-tubulin, or $\mathrm{EGFP}^{+}$cilia were collected and then collapsed to create maximum projection images that were saved as tiff files and subsequently analyzed using Image J64 (http://rsbweb.nih. gov/ij). We analyzed the brains of $\mathrm{P} 1$ and $\mathrm{P} 14$ electroporated mice (6-8 collapsed $z$-stack images/brain). Cilia lengths were measured in pixels by tracing $\mathrm{ACIII}^{+}, \alpha$-tubulin ${ }^{+}$, or EGFP ${ }^{+}$structures. The pixel values were converted to micrometers and were plotted as the mean \pm SEM. for each group. A one-way ANOVA (with Fisher's PLSD post hoc analysis) was used to compare groups. A $p$ value $<0.05$ was considered significant.

Western blots. Protein lysates were prepared from mouse cortex by homogenizing tissue in $1 \times$ RIPA buffer (Cell Signaling Technology). Lysate samples (10 $\mu \mathrm{g}$ of total protein/lane) were separated on $4-12 \%$ NuPAGE gels (Invitrogen) and transferred onto PVDF membranes using an iBlot (Invitrogen). Blots were blocked in Tris-buffered saline containing $0.1 \%$ Tween (TBST) and 5.0\% BSA (w/v) for $1 \mathrm{~h}$ at room temperature and were then incubated overnight at $4^{\circ} \mathrm{C}$ with one of the following primary antibodies diluted in TBST containing 2.5\% BSA: rabbit antiKif3a (1: 1000; Protein Tech); rabbit anti-TULP3 (1: 500; gift from J Eggenschwiler); rabbit anti-cytoplasmic dynein (74.1) (1:5000; Covance); rabbit anti-IFT88 (1:1500, Covance); mouse $\beta$-actin (1:10,000; Sigma). The next day, the blots were washed with TBST, incubated for $1 \mathrm{~h}$ at room temperature with appropriate HRP-conjugated secondary antibodies (1;10,000; Bio-Rad), and were developed using an ECL-Plus chemiluminescence kit according to the manufacturer's instructions (GE Healthcare). Images of the blots were captured and analyzed using an Alpha Innotech FluorChemQ Imaging System (ProteinSimple). The signal intensities of the protein bands of interest were quantified and normalized to the intensity of the $\beta$-actin on the same blot, which served as a loading control. Each protein sample was analyzed a minimum of three times.

Sholl analysis. To visualize cell morphology, cells were electroporated in utero with vectors encoding either EGFP or mRFP alone $(0.5 \mu \mathrm{g} / \mu \mathrm{l})$, or one of these vectors was paired with a vector encoding either ACIII: EGFP, 5HT6:EGFP, SSTR3:EGFP, EGFP:dnKif3a, or mCher(AU1)-2AdnKif3a $(2 \mu \mathrm{g} / \mu \mathrm{l})$. Sholl analyses were performed as previously described (Sarkisian and Siebzehnrubl, 2012). Briefly, from several experiments, fixed EGFP ${ }^{+}$or $\mathrm{mRFP}^{+}$cultured neurons selected from 4 to 8 coverslips ( $\sim 10-15$ neurons/coverslip) were photographed using an Olympus IX81 spinning disc confocal microscope fitted with a $40 \times$ dry objective. All raw images of $\mathrm{EGFP}^{+}$or $\mathrm{mRFP}^{+}$cells were resampled to obtain smaller, higher resolution grayscale images (e.g., 18.667" $\times 14.222$ " at 72 pixels/in to 3 " $\times 2.286$ " at 300 pixels/in). The grayscale images were thresholded to create high-contrast, binary images using Adobe Photoshop (Version 11.01) and were saved as tiff files. Images were then opened in Image J64 (http://rsbweb.nih.gov/ij) and analyzed using the Sholl Analysis plugin. The intersections of each cell's processes with concentric rings placed every $10 \mu \mathrm{m}$ up to $200 \mu \mathrm{m}$ from a point positioned in the center of each soma was counted, and the means of the various treatment groups were compared using two-way ANOVA (with Fisher's PLSD post hoc analysis), with $p<0.05$ considered significant.

\section{Results}

Overexpression of neuronal cilia GPCRs in developing mouse cortical neurons dramatically increases cilia length and disrupts cilia morphology

In this study, we targeted neocortical neurons and their cilia by delivering ciliary genes to developing E15.5 neural progenitors using in utero electroporation. The effects of expression of these genes by the pyramidal neurons were examined in culture or in situ at different postnatal stages of neocortical development (Fig. $1 A$ ). We found that expression of control plasmids encoding cytoplasmic EGFP by electroporated neurons did not induce any gross morphological changes in the cilia of these cells or alter the normal position of the cilia on the soma, which emerges near the base of the apical dendrite (Fig. $1 B$ ). In addition, the staining patterns for ACIII and pericentrin in $\mathrm{EGFP}^{+}$, control neurons, and neighboring nonelectroporated pyramidal neurons in layers $2 / 3$ were similar; ACIII was enriched in the axoneme and pericentrin was localized to the basal body (Anastas et al., 2011; Arellano et al., 2012) (Fig. 1B). We also observed that cytoplasmic EGFP was not detected in $\mathrm{ACIII}^{+}$cilia (Fig. 1B).

5HT6 and SSTR 3 receptors are normally expressed in the neocortex of early postnatal brain (Breunig et al., 2008; Riccio et al., 2009; Stanić et al., 2009; Anastas et al., 2011) and localize to the plasma membranes of neuronal primary cilia (Hamon et al., 1999; Handel et al., 1999; Brailov et al., 2000). We previously noted that overexpression of GPCRs in immortalized cell lines induced abnormal growth of the cilia of these cells. In this experiment, we used in utero electroporation to deliver bicistronic $2 \mathrm{~A}$ vectors encoding mCherry and either SSTR3:EGFP or 5HT6: EGFP to the brains of E15.5 mice to determine whether similar changes in the cilia of developing neurons would occur if we overexpressed GPCRs in these cells. Examination of electroporated neurons in layers $2 / 3$ of P14 neocortex revealed that both 5HT6:EGFP and SSTR3:EGFP were trafficked into the cilia (Fig. $1 C, D$ ); however, unlike 5HT6:EGFP, SSTR3:EGFP also appeared to be diffusely distributed throughout the somas and neurites of the electroporated cells (Fig. 1D). Notably, the cilia elaborated by neurons expressing 5HT6:EGFP were not only significantly longer than those of neurons expressing SSTR3:EGFP but were also abnormally branched (Fig. 1E,F). The robust primary and secondary order branching of 5HT6: $\mathrm{EGFP}^{+}$cilia occurred at varicosities that were distributed along the lengths of the cilia (Fig. 
A
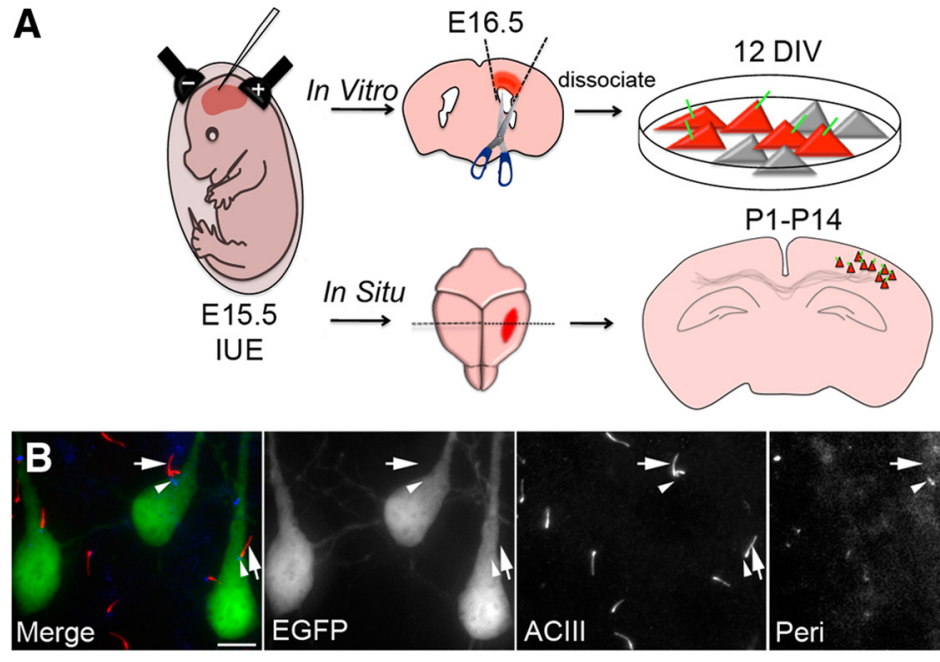

5HT6:EGFP
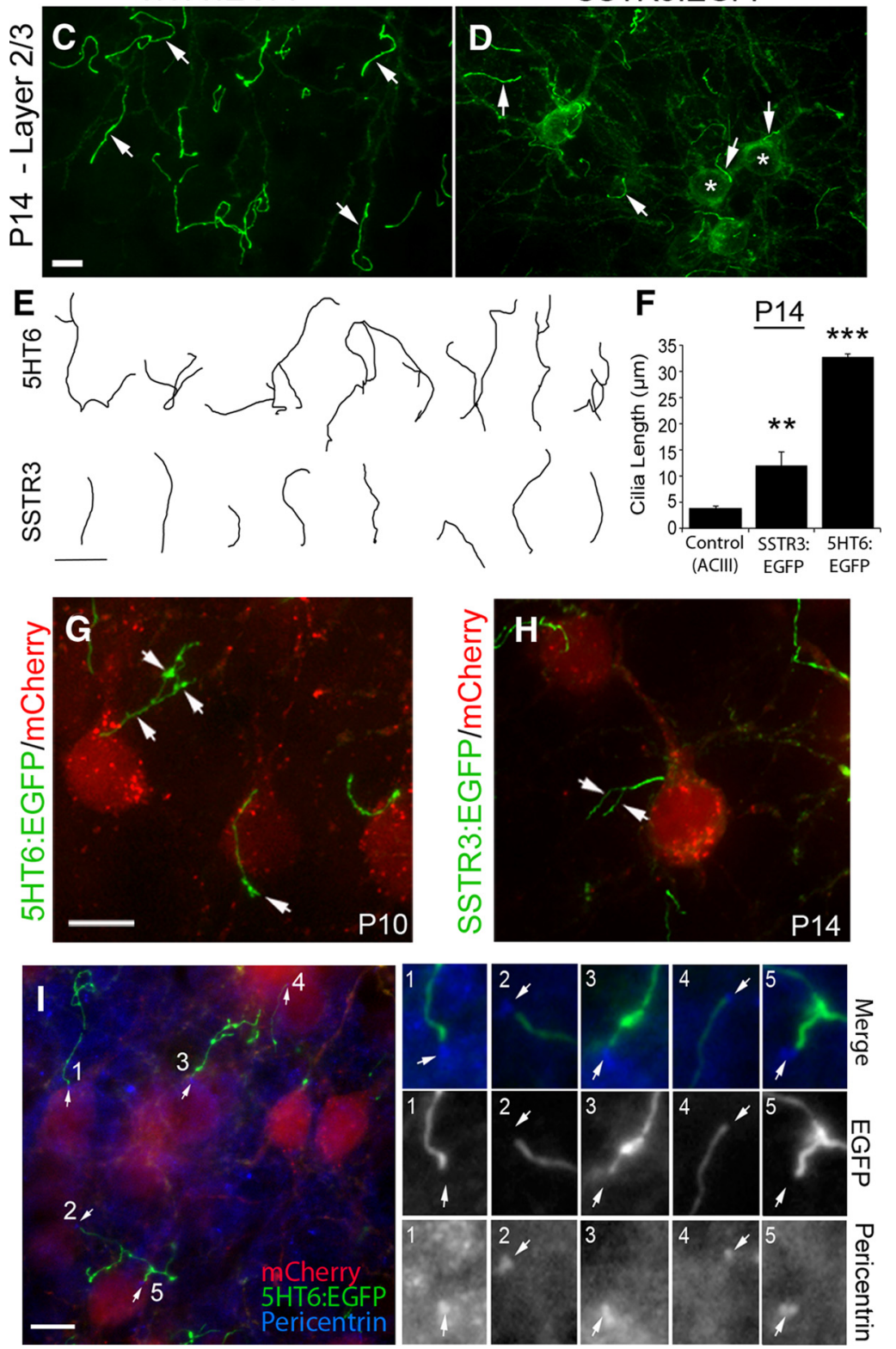

Figure 1. Overexpression of $5 \mathrm{HT} 6$ and SSTR3 in mouse neocortical neurons induces abnormal growth of their primary cilia. $\boldsymbol{A}$ Flow diagram of electroporation and experimental procedures used to induce and analyze the effects of overexpression of ciliary
$1 C, G)$. Branching of the cilia of neurons expressing SSTR3:EGFP, although not common, was occasionally observed (Fig. $1 H)$. We confirmed that the cilia-like processes elaborated by the electroporated cells were indeed cilia by staining the cells for pericentrin. Examination of the stained cells showed that pericentrin was localized at the base of all hyperelongated $\mathrm{EGFP}^{+}$organelles (Fig. 1I). In sum, our data show that overexpression of ciliary GPCRs in developing neocortical neurons dramatically alters ciliogenesis, inducing growth of cilia that are abnormally long and branched.

\section{Aberrant lengthening of neuronal cilia by GPCR overexpression is linked to} enhanced IFT function

While conducting our cortical experiments, we found that overexpression of 5HT6:EGFP and SSTR3:EGFP in NIH3T3 cells induced changes in the structures and lengths of their cilia that were similar to those observed in neurons (Fig. $2 A, B, G)$. We took advantage of this observation and used these cells as a model system to examine possible factors that could explain the effects of overexpression

\section{$\leftarrow$}

GPCRs on ciliogenesis in cultured and in situ neocortical neurons. Neurons analyzed in culture were dissected from electroporated cortex at E16.5, dissociated, and cultured up to 12 DIV. Neurons in situ were analyzed in sections of brains between P1 and P40 electroporated mice. $\boldsymbol{B}$, Examples of layer $2 / 3$ neurons electroporated at E15.5 with a vector encoding EGFP and labeled at P14. EGFP ${ }^{+}$pyramidal neurons show normal positioning and morphology of $\mathrm{ACIII}^{+}$cilia (red, arrows) with pericentrin ${ }^{+}$basal bodies (blue, arrowheads) near the base of the apical dendrite, and are comparable to neighboring nonelectroporated neurons. EGFP does not colocalize with ACIII in the EGFP ${ }^{+}$neurons. C, D, E15.5 cortices were electroporated with vectors encoding either 5HT6:EGFP (C) or SSTR3:EGFP (D) under control of the EF1 $\alpha$ promoter and were analyzed in situ at P14. C, Example of layer 2/3 neurons overexpressing 5HT6: EGFP, which is enriched in cilia (arrows). $D$, Example of layer 2/3 neurons overexpressing SSTR3:EGFP, which is detected in cilia (arrows) and throughout the cell bodies $\left.{ }^{*}\right)$. $\boldsymbol{E}$, Tracings of $\mathrm{EGFP}^{+}$cilia elongated by neurons expressing either 5HT6: EGFP and SSTR3:EGFP. Scale bar, $10 \mu \mathrm{m}$. F, Comparison of cilia lengths from control $\left(\mathrm{ACIII}^{+}\right)$, SSTR3:EGFP ${ }^{+}$, and 5HT6: EGFP $^{+}$neurons in layers $2 / 3$ of P14 neocortex. ${ }^{* *} p<0.01$ (ANOVA). ${ }^{* * *} p<0.001$ (ANOVA). $\boldsymbol{G}, \boldsymbol{H}$, Higher-magnification confocal $z$-stacks of branching cilia with varicosities (arrows) synthesized by mCherry ${ }^{+}$pyramidal neurons expressing either 5HT6:EGFP $(\boldsymbol{E})$ or SSTR3:EGFP $(\boldsymbol{F})$. Scale bar, $10 \mu \mathrm{m}$. $\boldsymbol{I}$, Sections of $\mathrm{P} 14$ neocortex containing $\mathrm{mCherry}{ }^{+}$neurons (red) with abnormally long and malformed 5HT6:EGFP ${ }^{+}$cilia (green) were immunostained for pericentrin (blue). Five $\mathrm{EGFP}^{+}$cilia with basal bodies were numbered, and their magnified images are displayed as separate channels (3 images) grouped vertically by cilium on the right. Pericentrin ${ }^{+}$basal bodies are present at the base of each EGFP ${ }^{+}$cilium $(I$, arrows). Scale bar, $10 \mu \mathrm{m}$. 

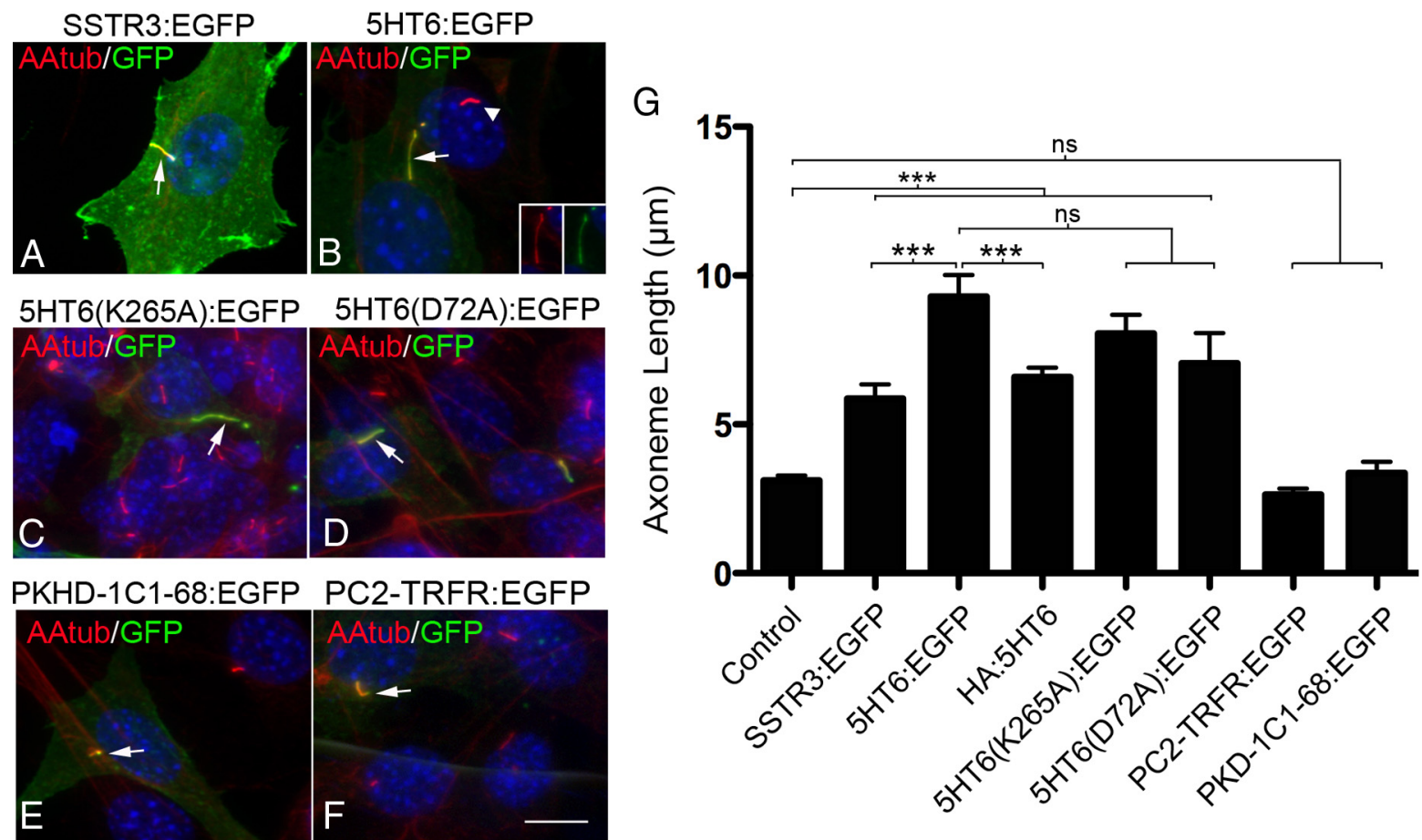

Figure 2. Cilia growth induced by GPCR overexpression is not significantly affected by loss of GPCR function or the presence of protein tags. (A-F) Representative confocal images of NIH3T3 cells expressing the proteins indicated above each panel whose expression was driven by the CMV promoter. All cells were immunostained with antibodies against the axoneme-enriched protein, acetylated $\alpha$ tubulin (AAtub) (red) and GFP (green). Nuclei were labeled with DAPI (blue). $\boldsymbol{A}$, Cilium of a cell transfected with a vector encoding SSTR3:EGFP (arrow). B, Cilium of cell overexpressing 5HT6:EGFP (arrow) adjacent to a cilium of a nontransfected control cell (arrowhead). Insets, Single-channel EGFP and AAtub staining of the cilium of the transfected cell. $C, \boldsymbol{D}$, Cilia elaborated by cells overexpressing the signaling defective 5HT6 receptors, 5HT6(K265A):EGFP (C) or 5HT6(D72A):EGFP (D) (arrows). E, F, 0verexpression of EGFP fused to fibrocystin (PKHD-1C1-68:EGFP) (E) or human transferrin receptor (PC2-TRFR:EGFP) $(\boldsymbol{F})$, two noncilia proteins fused to a cilia localization signal. Scale bar (in $\boldsymbol{F}$ ), $10 \mu \mathrm{m}$. $\boldsymbol{G}$, Mean axoneme lengths of cilia produced by cells expressing the experimental vectors shown in panels $\boldsymbol{A}-\boldsymbol{F}$ and HA:5HT6. From left to right, $n=50,34,44,56,38,22,26$, and 30 cilia analyzed/group, respectively. Error bar indicates mean $\pm S E M$. ${ }^{* * *} p<0.001$ (one-way ANOVA). ns, Not significant.

of these receptor proteins on ciliogenesis. To determine whether the function of the overexpressed receptor was critical to obtaining the cilia phenotype induced by overexpression of 5HT6, we examined the effects of overexpression of two signaling defective 5HT6 receptors, K265A and D72A, on ciliogenesis. We also determined whether fusion of 5HT6 to protein tags contributed to the cilia phenotype. Finally, we examined the specificity of this effect by overexpressing nonciliary fusion proteins targeted to the cilia by ciliary targeting sequences; the two proteins examined were EGFP fused to the fibrocystin ciliary targeting sequence (PKD-1C1-68:EGFP), a protein that is normally excluded from neuronal cilia (e.g., Fig. $1 B$ ), and the transferrin receptor fused to EGFP, a single transmembrane-spanning protein not normally found in cilia (PC2-TRFR:EGFP). The results of these experiments suggest that the abnormal cilia growth that accompanies overexpression of 5HT6:EGFP is not dependent on the activity of this receptor (Fig. 2C,D, G) and is only modestly influenced by the size or the position of the EGFP or HA protein tags fused to the receptor (Fig. $2 G$ ). More importantly, we found that abnormal cilia growth could not be induced in cells overexpressing nonciliary transmembrane (PC2-TRFR:EGFP) or soluble proteins (PKD-1C1-68:EGFP) targeted to the cilia (Fig. 2E, F, G).

Trafficking of GPCRs within the cilium is thought to depend on IFT, a process that is mediated by proteins that are also critical for promoting ciliogenesis (Nachury et al., 2007; Berbari et al., 2008b; Mukhopadhyay et al., 2010; Garcia-Gonzalo and Reiter, 2012). We next asked whether overexpression of GPCRs in neurons alters IFT in a manner that would support the increased growth of the primary cilia of these cells. Western blot analyses of proteins extracted from electroporated cortex revealed that the levels of Kif3a, an anterograde motor subunit required for neuronal ciliogenesis (Chizhikov et al., 2007; Davenport et al., 2007; Han et al., 2008; Kumamoto et al., 2012), were significantly elevated within subdissected regions of P14 cortex overexpressing either SSTR3:EGFP or 5HT6:EGFP ( $n=3$ or 4 pooled hemispheres/group) compared with extracts from electroporated and nonelectroporated control tissues (Fig. $3 A-D$ ). We also found that the levels of other IFT-associated proteins were elevated in these cortical regions: the retrograde transport protein cytoplasmic dynein, D1 IC74 (Pazour et al., 1998; Tai et al., 1999; Grissom et al., 2002; Makokha et al., 2002); the IFT complex B protein, IFT88 (Kozminski et al., 1993; Willaredt et al., 2008; Goetz and Anderson, 2010; Satir et al., 2010; Taschner et al., 2012); and the GPCR ciliary trafficking protein, Tubby-like protein 3 (TULP3) (Mukhopadhyay et al., 2010). Examination of neurons overexpressing 5HT6:EGFP that were stained with IFT88 antibodies showed that this transport protein was localized to the cilium and was distributed along its entire length (Fig. $3 E, F$ ). Together, our Western and immunohistochemical data show that overexpression of 5HT6:EGFP induces increased levels of several proteins associated with IFT and suggest that these proteins are distributed to the cilia and would support increased IFT and cilia growth. Interestingly, the levels of TULP3, which were barely detectable in control cortex and cortex overexpressing 5HT6: EGFP, were increased in cortices overexpressing SSTR3:EGFP (Fig. 3D).

We next asked whether overexpressing GPCRs in neurons not yet elaborating cilia could trigger IFT and premature ciliogenesis. In 

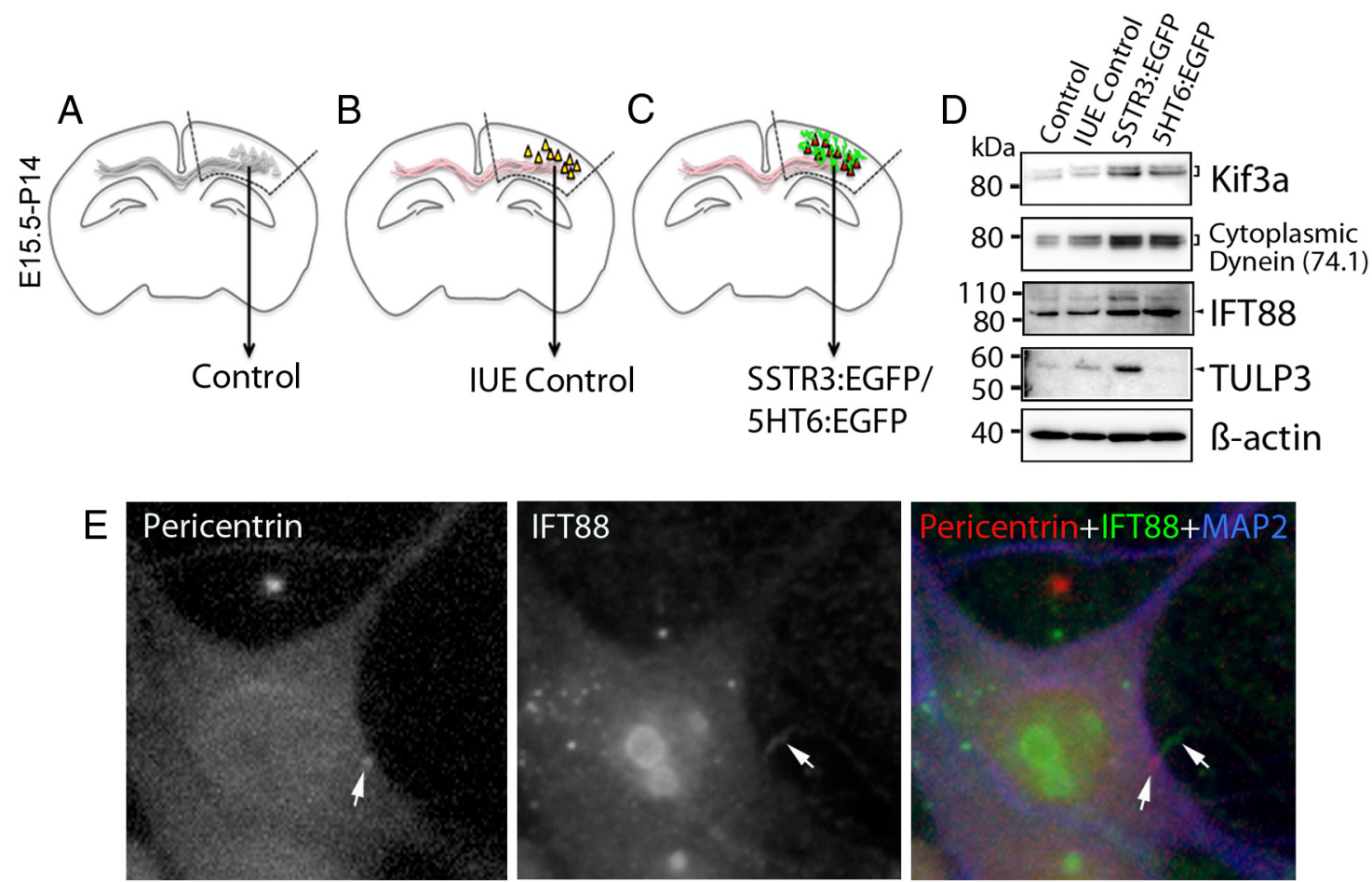

$\mathrm{F}$
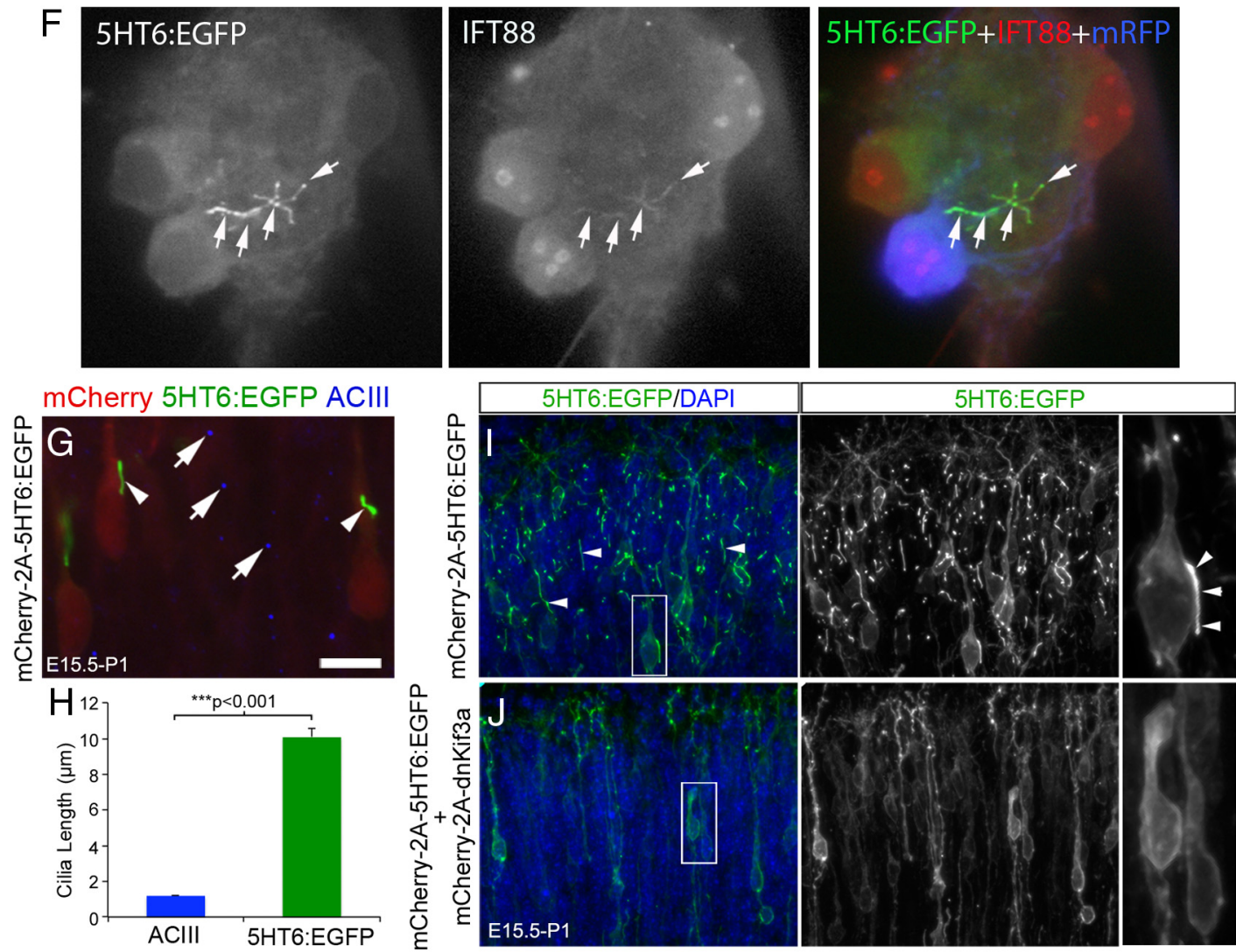

Figure 3. GPCR overexpression induces upregulation of IFT proteins and premature cilia lengthening. $A-D$, Comparisons were made between protein expression in nonelectroporated control cortex $(\boldsymbol{A})$, fetal cortex that was electroporated at E15.5 with either a vector encoding EGFP and mCherry:AU1 (in utero electroporation control) (B), or mCherry:AU1 and either SSTR3:EGFP or 5HT6:EGFP (C). Expression of all transgenes was under the control of the EF1 $\alpha$ promoter. Hyphenated lines indicate cortical regions of P14 brains that were used to prepare the protein lysates analyzed by Western blot. D. Western blots (10 $\mu \mathrm{g}$ of total protein/group) were probed for proteins associated with either anterograde (Kif3a) or retrograde (cytoplasmic dynein, D1 IC74) IFT complex B protein (IFT88), or GPCR trafficking into cilia (TULP3). $\beta$-Actin was used as a loading control. E, Cultured, nonelectroporated control cortical neuron immunostained for pericentrin (basal body, red), IFT88 (green), and the neuronal marker, MAP2 (blue). The arrow in the middle panel points to an IFT88 ${ }^{+}$cilium extending from a pericentrin ${ }^{+}$basal body (arrow left panel). $\boldsymbol{F}$, Example of an abnormally long, branched 5HT6:EGFP ${ }^{+}$cilium synthesized by a cultured neuron expressing 5HT6:EGFP (green) under the control of the CMV promoter and mRFP (pseudocolored blue). IFT88 (red) and EGFP were colocalized along the length and branches of the cilium (white arrows). Scale bar, $5 \mu \mathrm{m}$. G, E15.5 brains were electroporated with a vector encoding mCherry(AU1)-2a-5HT6: EGFP. At P1, electroporated brains were sectioned and stained with an antibody against ACIII. Examination of the upper layers of the cortical plate revealed $\mathrm{mCherry}{ }^{+}$(Figure legend continues.) 

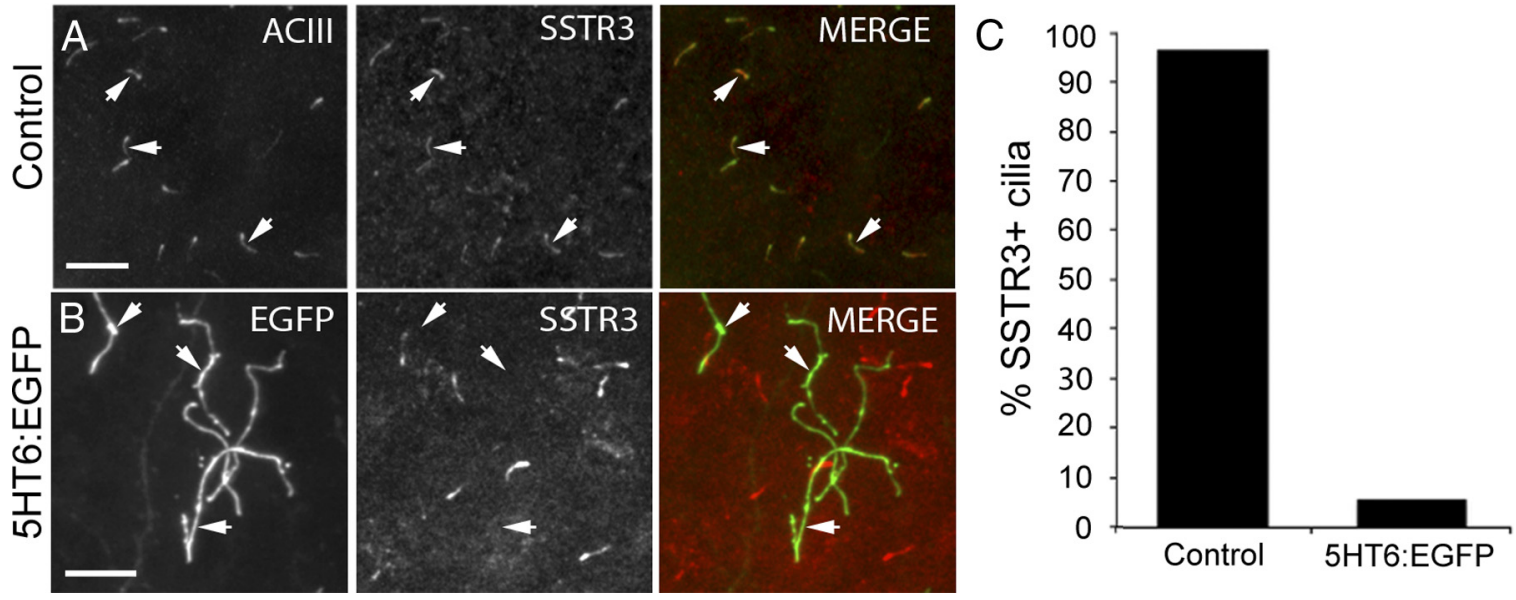

Figure 4. Cilia of neurons overexpressing 5HT6:EGFP do not contain detectable levels of SSTR3. A, Control P14 neocortex stained with antibodies against ACIII (green) and SSTR3 (red). The majority of $\mathrm{ACIII}^{+}$cilia are also SSTR3 ${ }^{+}$(arrows). Scale bar, $10 \mu \mathrm{m}$. B, Cilia synthesized by neurons expressing 5HT6:EGFP (arrows) are not correspondingly SSTR3 ${ }^{+}$. Scale bar, $10 \mu \mathrm{m}$. C, The percentage of $\mathrm{ACIII}^{+}$control $(n=1056)$ or $5 \mathrm{HT} 6: \mathrm{EGFP}^{+}(n=688)$ cilia that are also SSTR3 ${ }^{+}$.

normal developing neocortex, neurons begin to elaborate "procilia" at P1 that resemble puncta when visualized by ACIII immunostaining (Arellano et al., 2012). To address this question, we electroporated E15.5 neocortex with a vector encoding mCherry and 5HT6: EGFP (mCherry(AU1)-2A-5HT6:EGFP) and examined the cilia of the electroporated neurons at P1. We found that many of the 5HT6: $\mathrm{EGFP}^{+}$cilia that were elaborated by mCherry ${ }^{+} \mathrm{P} 1$ neurons were significantly longer than the $\mathrm{ACIII}^{+}$procilia associated with neighboring, nonelectroporated neurons (Fig. $3 G, H$ ), a result showing that overexpression of 5HT6 was able to induce premature ciliogenesis. To determine whether IFT was essential to support the early onset of ciliogenesis in developing layer $2 / 3$ neurons, we electroporated neurons at E15.5 with either a plasmid encoding 5HT6:EGFP (mCherry(AU1)-2A-5HT6:EGFP) to visualize cilia or a mixture of this plasmid and one encoding dominant-negative Kif3a (mCherry(AU1)-2A-dnKif3a). Dominant-negative Kif3a (dnKif3a) is a truncated, nonfunctional form of Kif3a that does not support IFT and has recently been reported to block ciliogenesis in adult-born granule neurons (Kumamoto et al., 2012). As expected, examination of neurons in P1 brains expressing 5HT6:EGFP alone revealed numerous cells bearing long, $\mathrm{EGFP}^{+}$cilia (Fig. 3I). In contrast, neurons coexpressing 5HT6:EGFP and dnKif3a failed to localize 5HT6:EGFP to the developing cilia; in these cells, 5HT6:EGFP was largely restricted to the neurons' cell bodies (Fig. $3 J$ ). This result indicates that 5HT6-induced ciliogenesis in $\mathrm{P} 1$ neocortical neurons requires IFT.

Collectively, these data show that the premature cilia growth in developing neocortical neurons that is induced by overexpression of ciliary GPCRs is accompanied by increased levels of IFT proteins, which may reflect a demand for increased transport of the GPCRs into or within the cilia.

(Figure legend continued.) neurons (red) that possessed longer 5HT6:EGFP ${ }^{+}$cilia (arrowheads) than their neighboring nonelectroporated cells whose ACIII-stained cilia appear punctate (blue, arrows). Scale bar, $10 \mu \mathrm{m}$. $\boldsymbol{H}$, Comparison of the lengths of the cilia of neurons overexpressing 5HT6:EGFP and control neurons: ***Student's t test. (I) Section of brain electroporated and processed as described for $\mathbf{G}$, but not including the red channel used to visualize mCherry. Numerous, often long cilia (arrows) were present in the upper layers of the cortical plate.J, P1 neurons in the upper cortical plate that were coelectroporated at E15.5 with vectors encoding mCherry and 5HT6:EGFP ( $m$ Cherry(AU1)-2a-5HT6:EGFP) and mCherry and dnKif3a (mCherry(AU1)-2a-dnKif3a). The elongated 5HT6:EGFP ${ }^{+}$cilia of neurons expressing 5HT6: EGFP alone $(I)$ are not observed in cells coexpressing 5HT6:EGFP and dnKif3a.
5HT6 overexpression is associated with a marked decrease in ciliary SSTR3 and ACIII localization

Next, we asked whether the abnormal length and branching of 5HT6:EGFP ${ }^{+}$cilia could compromise trafficking of other ciliatargeted molecules to the cilia that are required for normal cilia function. In normal neocortex, SSTR3 is trafficked into the majority $\left(>90 \%\right.$ ) of $\mathrm{ACIII}^{+}$neuronal cilia (Fig. $4 A, C$ ) (Stanić et al., 2009; Einstein et al., 2010). Thus, in our first experiment, we examined the cilia of neurons overexpressing 5HT6:EGFP for the presence of SSTR3. Strikingly, we found that the cilia elaborated by $\sim 95 \%$ of the neurons overexpressing 5HT6:EGFP failed to stain for SSTR3 (Fig. 4B,C), an observation that suggests that overexpression of 5HT6:EGFP disrupts trafficking of SSTR3 into the cilium.

In view of this result, we next asked whether overexpression of 5HT6:EGFP alters the levels of other cilia-targeted signaling molecules in the cilia. One key signaling molecule associated with primary cilia is ACIII. ACIII, which is localized to the primary cilia of most neurons, is thought to participate in the signal transduction cascades triggered by many receptors in the ciliary membrane (Berbari et al., 2007; Bishop et al., 2007; Ou et al., 2009; Arellano et al., 2012). Given its central role in cilia function, we asked whether levels of ACIII are altered in the cilia of cortical neurons overexpressing either 5HT6:EGFP or SSTR3:EGFP. Intriguingly, ACIII was not detected in the cilia of layer $2 / 3$ neurons overexpressing 5HT6:EGFP (Fig. 5A) but was present in the cilia of neurons overexpressing SSTR3:EGFP (Fig. 5B). Quantification of ACIII staining revealed that $>90 \%$ of the cilia produced by neurons overexpressing SSTR3:EGFP were $\mathrm{ACIII}^{+}$, whereas $<10 \%$ of the cilia elaborated by neurons overexpressing 5 HT6: EGFP were $\mathrm{ACIII}^{+}$(Fig. 5C). Collectively, these data suggest that the growth and structural changes observed in the primary cilia of neurons overexpressing 5HT6:EGFP are accompanied by a dramatic reduction in ciliary ACIII levels that we predict would compromise the signaling capabilities of these organelles.

\section{Neurons with long, malformed cilia and those with blocked} cilia formation exhibit abnormal dendritic outgrowth

Recent studies suggest that abnormal neuronal ciliogenesis is associated with dendrite outgrowth defects (Massinen et al., 2011; Kumamoto et al., 2012). To determine whether the abnormal ciliogenesis induced by overexpression of GPCRs in neocortical neurons 

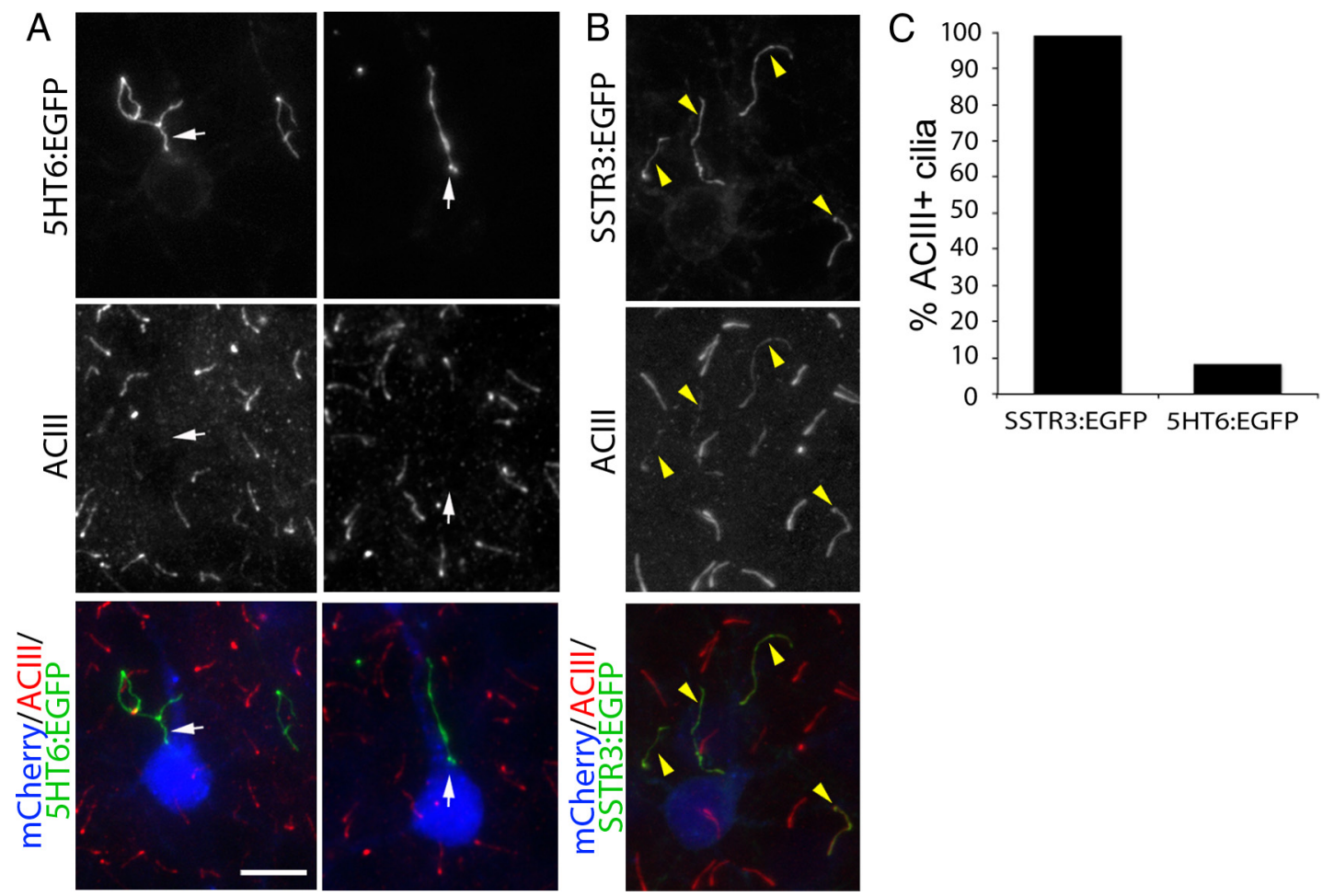

Figure 5. Cilia of neurons overexpressing 5HT6:EGFP do not contain detectable levels of ACIII. The brains of E15.5 embryos were electroporated with vectors encoding either 5HT6:EGFP or SSTR3:EGFP under control of the EF1 $\alpha$ promoter and were immunostained for ACIII at P14. A, Pyramidal neurons in layers 2/3 of neocortex expressing mCherry:AU1 (blue) and 5HT6:EGFP (green). Sections were immunostained for ACIII (red), which normally is enriched in cilia of virtually all neocortical neurons. White arrows point to 5 HT6:EGFP ${ }^{+}$cilia projecting from mCherry:AU1 ${ }^{+}$neurons that lack detectable ACIII staining. Scale bar, $10 \mu \mathrm{m}$. B, Pyramidal neurons in layers 2/3 of neocortex expressing mCherry:AU1 (blue) and SSTR3:EGFP (green). SSTR3:EGFP ${ }^{+}$cilia also stain for ACIII (yellow arrowheads). C, The percentage of SSTR3:EGFP ${ }^{+}(n=123)$ or $5 \mathrm{HTT}: \mathrm{EGFP}^{+}(n=89)$ cilia that are also $\mathrm{ACIII}^{+}$.

is accompanied by changes in dendrite outgrowth, we compared the dendritic arbors of cortical neurons that had been electroporated at E15.5 with vectors encoding either EGFP (control) (Fig. 6A), SSTR3: EGFP (Fig. 6B), or 5HT6:EGFP (Fig. 6C) and then cultured for $12 \mathrm{~d}$. Visual comparisons of the confocal images of these neurons revealed that overexpression of 5HT6:EGFP dramatically reduced dendrite outgrowth, whereas overexpression of SSTR3:EGFP produced moderate reductions in dendrite outgrowth compared with controls. Using Sholl analyses to quantify these observations, we found that dendritic outgrowth from 5HT6:EGFP and SSTR3:EGFP neurons was significantly less than from control neurons $(p<0.001$; two-way ANOVA) (Fig. 6E). The complexity of the dendritic arbors elaborated by neurons overexpressing SSTR3:EGFP resembled that of control neurons within a radius of $\sim 20 \mu \mathrm{m}$ of the soma center but then abruptly decreased between $\sim 30$ and $150 \mu \mathrm{m}$ of the soma center. Within this latter region, the complexity of the dendritic arbors was greater than that observed for 5HT6:EGFP neurons but less than that of control neurons. Within $100 \mu \mathrm{m}$ of the soma, the complexity of the dendritic arbors elaborated by SSTR3:EGFP ${ }^{+}$ neurons was significantly greater than that exhibited by 5HT6: $\mathrm{EGFP}^{+}$neurons. We also found that overexpression of 5HT6:EGFP ( $n=80$ cells) compared with EGFP alone ( $n=80$ cells) hindered formation of dendritic arbors by neurons electroporated at E13.5 that were destined to form the deeper layers of neocortex (data not shown). This observation shows that the effects of overexpression of 5HT6:EGFP on dendrite formation are not limited to neurons that populate layers $2 / 3$ but are also observed in other neocortical neuron subtypes.

To determine whether the absence of a cilium would induce similar effects on the dendrite arbor formation, we electroporated developing cortical neurons with a vector encoding dnKif3a fused to EGFP (EGFP:dnKif3a). We found that overexpression of EGFP:dnKif3a in NIH3T3 cells and cultured neurons blocks ciliogenesis as evidenced by the absence of acetylated $\alpha$ tubulin and ACIII staining, respectively (data not shown). The dendritic arbors of neurons expressing EGFP:dnKif3a were significantly less complex than those of neurons overexpressing SSTR3:EGFP and control neurons (Fig. 6D,E). It is noteworthy that the effects of overexpression of 5HT6: EGFP on dendritic complexity, although the most severe, closely resembled those induced by overexpression of EGFP:dnKif3a. Collectively, our data suggest that developing neurons that either elongate malformed cilia or lack cilia fail to elaborate normal dendritic arbors.

\section{Coexpression of ACIII with 5HT6:EGFP but not dnKif3a reverses dendrite arbor defects}

We observed that the inability of neurons to arborize dendrites was most pronounced when their cilia were either both very long and branched or were absent. In either case, ACIII could not be detected in the cilia of these cells (Figs. 5 and 6). In contrast, the cilia of neurons overexpressing SSTR3:EGFP, although longer than control cilia, were ACIII ${ }^{+}$, and their dendritic arbors were less severely attenuated than those of neurons expressing either 5HT6:EGFP or dnKif3a. Thus, we asked whether overexpression of ACIII in neurons overexpressing 5HT6:EGFP could reverse the dendritic arbor defects exhibited by these neurons. First, we generated an EGFP-tagged ACIII construct which, unlike EGFP (Fig. 7A), was able to localize to cilia in cultured electroporated neurons (Fig. $7 B$ ). We then electroporated E15.5 cortex with a mixture of vectors encoding ACIII:EGFP, 5HT6:EGFP, and mRFP, harvested the electroporated neurons at E16.5, and examined them after $12 \mathrm{~d}$ in culture. Examination of $\mathrm{mRFP}^{+}$neurons 


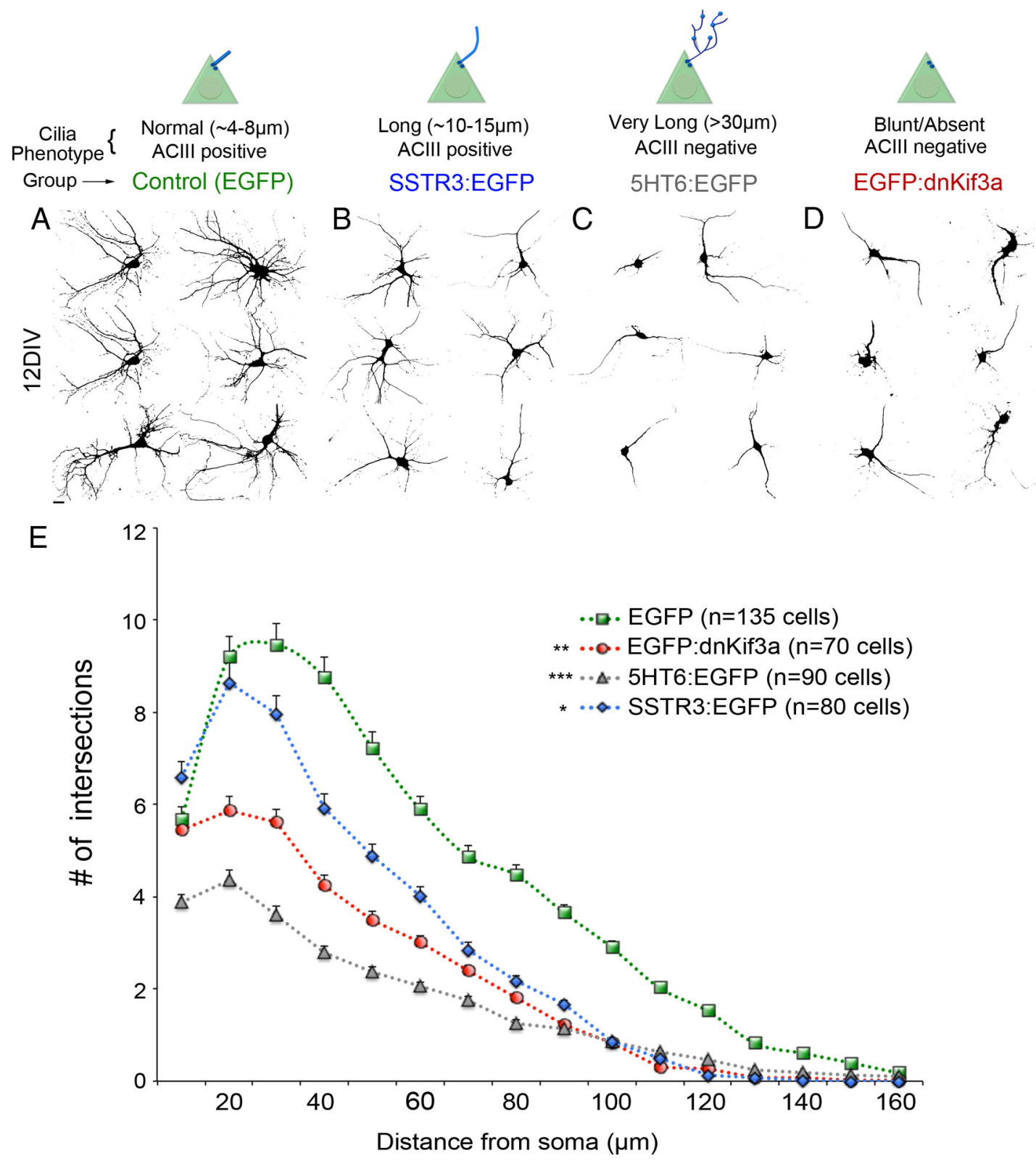

Figure 6. 5HT6, SSTR3, and dnKif3a overexpression reduces dendrite outgrowth of cultured cortical neurons. Neurons were electroporated at E15.5 with a vector encoding EGFP (Control) or the vector encoding EGFP plus vectors encoding SSTR3:EGFP, 5HT6:EGFP, or EGFP:dnKif3a under the CMV promoter. Typical cilia phenotypes associated with each group are indicated. At E16.5, cells were harvested, dissociated, and fixed after 12 DIV. Confocal images of EGFP ${ }^{+}$cells were converted to black-and-white images. $\boldsymbol{A}-\boldsymbol{D}$, Examples of neurons at 12 DIV expressing $(\boldsymbol{A})$ EGFP alone, ( $\left.\boldsymbol{B}\right)$ SSTR3:EGFP, (C) 5HT6:EGFP, and (D) EGFP:dnKif3a. E, Sholl analyses reveal the extent of arborization of EGFP control (green line), SSTR3:EGFP (blue), dnKif3a (red), and 5HT6:EGFP (gray) neurons. $N=$ total number of cells analyzed. ${ }^{* * *} p<0.001$ versus EGFP (two-way ANOVA). ${ }^{* *} p<0.01$ versus EGFP (two-way ANOVA). ${ }^{*} p<0.05$, versus EGFP (two-way ANOVA).

revealed that $>90 \%$ of $\mathrm{EGFP}^{+}$cilia also stained positively for ACIII (Fig. 7C,D). Compared with neurons overexpressing ACIII:EGFP alone, whose cilia lengths were similar to control, coexpression of 5HT6:EGFP and ACIII:EGFP in neurons significantly reduced the lengths of the cilia elaborated by these cells compared with neurons expressing 5HT6:EGFP alone (Fig. 7E). As expected, in neurons coexpressing ACIII:EGFP and dnKif3a, we were unable to detect $\mathrm{ACIII}^{+}$cilia (Fig. $7 E$ ). These results indicate that coexpression of ACIII:EGFP with 5HT6:EGFP in neurons reduced the ciliary defects induced by overexpression of 5HT6:EGFP alone and increased the levels of ACIII in the cilium.

We next asked whether there were any differences in the dendritic arbors of neurons expressing ACIII:EGFP alone, 5HT6:EGFP alone, or ACIII:EGFP and 5HT6:EGFP. As shown above (Fig. 6C,E), we found that the dendritic arbors of neurons overexpressing 5HT6: EGFP alone were the most poorly arborized (Fig. $7 F$ ). In contrast, the dendritic arbors of neurons overexpressing ACIII:EGFP were significantly more elaborate than neurons expressing 5HT6:EGFP alone (Fig. 7F). Remarkably, the dendritic arbors of neurons coexpressing ACIII:EGFP and 5HT6:EGFP were significantly more arborized than those of neurons expressing 5HT6:EGFP alone, resembling those of neurons expressing ACIII:EGFP alone (Fig. 7F). To determine whether the effects of overexpression of ACIII on dendritic arborization were dependent on localization of the ACIII to the cilium, we examined the dendritic arbors of cultured neurons that had been coelectroporated with vectors encoding dnKif3a and ACIII:EGFP. Strikingly, we found that the dendritic processes elaborated by these neurons were not significantly different from those 

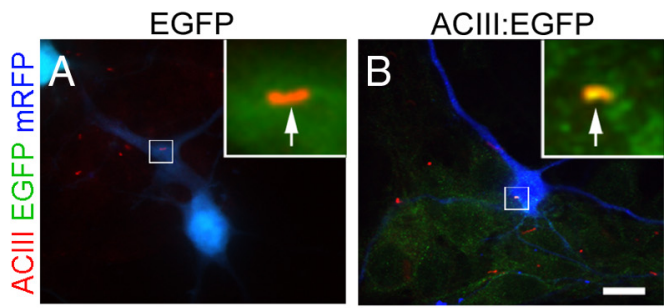

5HT6:EGFP+ ACIII:EGFP+mRFP
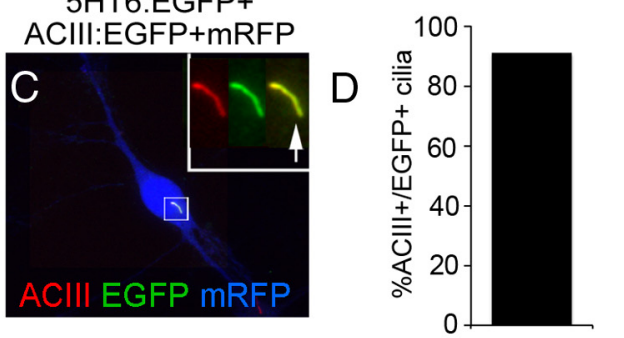

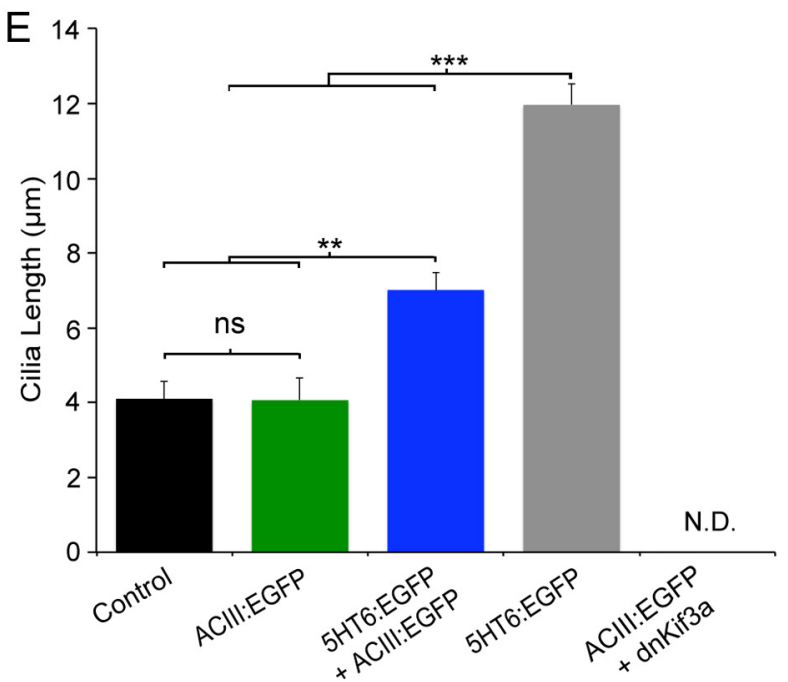

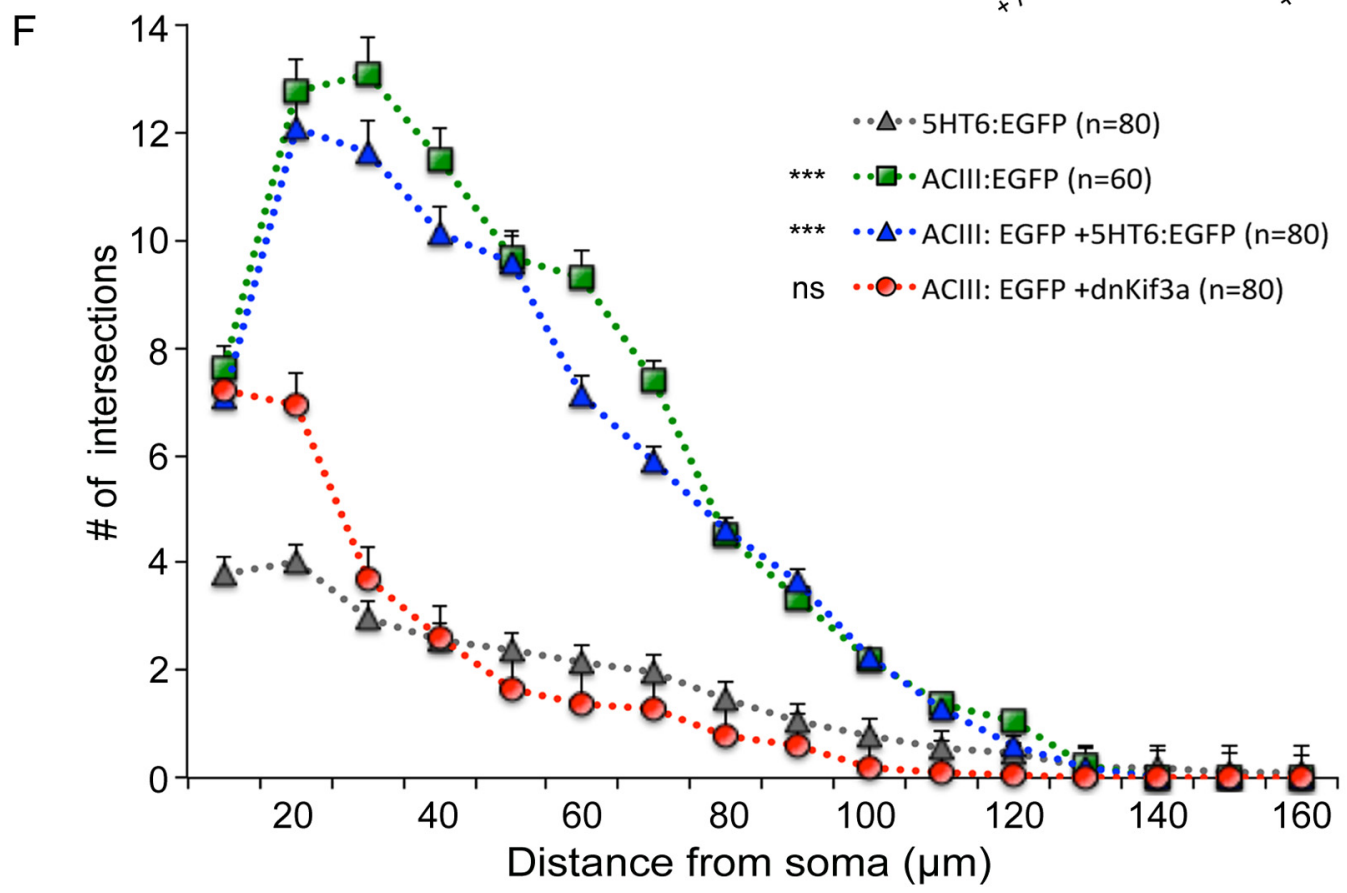

Figure 7. Coexpression of ACIII:EGFP with 5HT6:EGFP, but not dnKif3a, restores ciliary ACIII, cilia structure, and dendrite outgrowth. $A$, $B$, Neurons electroporated at E15.5 with vectors encoding either ( $A$ ) mRFP and EGFP or (B) mRFP and ACIII:EGFP. Electroporated neurons were cultured for 6 DIV, fixed, and immunostained for ACIII (red). Analyses of mRFP ${ }^{+}$neurons (blue) showed that EGFP did not traffic into the cilia as evidenced by an absence of colocalization with ACIII ( $\boldsymbol{A}$; arrow in inset). When fused to ACIII, the cilia were positive for both ACIII staining and EGFP fluorescence ( $\boldsymbol{B}$; arrow in inset). Scale bar (in $\boldsymbol{B}), 10$ $\mu \mathrm{m}$. C, Example of a cultured neuron coelectroporated with 5HT6:EGFP and ACIII:EGFP possessing a cilium that is positive for both ACIII staining and EGFP (inset shows higher magnification of cilia in individual channels and merge). D, Quantification of the number of cells coelectroporated with 5HT6:EGFP and ACIII:EGFP whose cilia were both $\mathrm{ACIII}^{+}$and EGFP ${ }^{+}(N=139$ of 153$)$. E, Comparisons of the lengths of the cilia elaborated by neighboring nonelectroporated (control) neurons $(n=142)$ or neurons transfected with vectors encoding mRFP plus ACIIl:EGFP ( $n=60)$, ACIII:EGFP and 5HT6:EGFP ( $n=120)$, 5HT6:EGFP $(n=120)$, or dnKif3a $(n=118)$ and cultured for 12 DIV. ${ }^{* *} p<0.01 .{ }^{* * *} p<0.001$. ns, Not significant; N.D., not determinable. F, Sholl analyses of the complexity of the dendritic arbors elaborated by neurons transfected with mRFP plus either 5HT6:EGFP (gray), ACIIl:EGFP (green), EGFP:dnKif3a + ACIll:EGFP (red), or ACIIl:EGFP + 5HT6:EGFP (blue) and maintained in culture for $12 \mathrm{~d}$ ( $n=$ number of cells analyzed). The complexity of the arbors of neurons expressing 5HT6:EGFP were statistically compared with those of the other groups using two-way ANOVA: ${ }^{* * *} p<0.001$. ns, Not significant).

elaborated by neurons overexpressing 5HT6:EGFP alone (Fig. 7F). Collectively, these results strongly suggest that the formation of normal dendritic arbors by developing cortical neurons requires ACIII to be localized to their cilia. Whether the regulation of arborization is mediated directly by ACIII or whether ACIII works in concert with other ciliary molecules to regulate dendrite arborization requires further investigation.

\section{Discussion}

The results of our study show that disruption of ciliogenesis in developing cortical neurons by either overexpressing cilia- associated GPCRs or by blocking IFT inhibits the ability of these neurons to form normal dendritic arbors. Overexpression of ciliary GPCRs in these neurons induces an upregulation of IFTassociated molecules and premature elongation of primary cilia by developing neurons. The most striking changes in cilia morphology were induced by overexpression of 5HT6:EGFP, which were accompanied by a lack of SSTR3 and ACIII in the cilia. Coexpression of ACIII:EGFP and 5HT6:EGFP reversed the abnormal dendrite phenotype associated with overexpression of 5HT6:EGFP alone. However, overexpression of ACIII:EGFP in neurons lacking cilia resulting from coexpression with dnKif3a 
was unable to reverse this dendritic phenotype. Collectively, our data suggest that the process of neuronal dendritogenesis is dependent on the ability of neurons to generate ACIII-enriched primary cilia. Mutations that disrupt ciliogenesis or the ability of signaling proteins to localize to the cilium are thus likely to alter dendritogenesis and therefore the ability of neurons to form normal network connections and brain circuitry.

\section{GPCR-induced changes in neuronal cilia length}

The primary cilia of cortical neurons in the postnatal brain elongate over a period of many weeks (Arellano et al., 2012; Kumamoto et al., 2012). Although many factors are thought to affect cilia length (Ou et al., 2009; Miyoshi et al., 2011; Sharma et al., 2011; Avasthi and Marshall, 2012), our data show that cilia length homeostasis is dramatically disrupted by overexpression of GPCRs. Our observation is consistent with and extends recent results showing that class A GPCRs (e.g., dopamine 1) can induce elongation of NIH3T3 primary cilia (Avasthi et al., 2012) and that the primary cilia of neurons in the amygdalae of $B B S 4^{-1-}$ mice become elongated because of increased ciliary accumulation of dopamine 1 receptors (Domire et al., 2011) (K. Mykytyn, unpublished observation). In contrast, the absence of neuronal cilia GPCRs does not appear to have an appreciable effect on cilia length homoeostasis. For example, the cilia of hippocampal or nucleus accumbens neurons in mice lacking either BBS2 or BBS4 appear normal, even though they do not contain detectable levels of SSTR3 or MCHR1 (Berbari et al., 2008b). Similarly, the primary cilia of neurons in SSTR3 knock-out mice also appear to be structurally normal (Einstein et al., 2010).

We found that overexpression of either SSTR3:EGFP or 5HT6:EGFP in neurons not only induced premature growth of their primary cilia but also increased expression levels of Kif3A, IFT88, and cytoplasmic dynein in these cells, all of which support IFT. Interestingly, we found increased levels of TULP3 in neocortical regions overexpressing SSTR3:EGFP, but not in those overexpressing 5HT6:EGFP. TULP3 binds to the IFT-A complex and promotes ciliary trafficking of SSTR3 and MCHR1 into neural cilia but not Smoothened (Smo) (Mukhopadhyay et al., 2010). The increase in TULP3 in neurons overexpressing SSTR3 could reflect differences between 5HT6 and SSTR3 transport within and/or to neuronal cilia, and suggests that the neuronal response induced by overexpression of specific GPCRs may be receptor specific.

Over the course of our experiments, we noticed that the cilia of neurons overexpressing 5HT6:EGFP were typically longer and more irregular than neurons overexpressing SSTR3:EGFP. The underlying cause(s) for this difference is not clear. It is possible that 5HT6 is trafficked into the cilia more efficiently or that neurons regulate the levels of expression of these GPCRs differently. An additional possibility is suggested by recent reports that active $\mathrm{G} \alpha_{\mathrm{s}}$ can bind tubulin and mobilize microtubule plus-ends (Dave et al., 2009; Yu et al., 2009; Dave et al., 2012). The 5HT6 receptor is coupled to Gs, whereas the SSTR3 receptor is coupled to Gi (Law et al., 1994). Thus, it is tempting to speculate that the dramatic effects of overexpression of 5HT6 on cilia formation are, at least in part, the result of an increase in the amount and activity of Gs within the cilium that leads to increased axoneme growth and demand for IFT proteins.

\section{GPCR overexpression may compromise neuronal cilia signaling}

It is likely that increased trafficking of ciliary GPCRs (especially 5HT6) into developing cilia alters the signaling properties of the cilia. In addition to ciliary branching and varicosities, we found that native SSTR3 was rarely detected in the cilia of neurons overexpressing 5HT6:EGFP. The reduced levels of SSTR3 in these cilia could reflect impaired trafficking of SSTR3 into the cilium in the presence of the more abundant 5HT6:EGFP receptor, which would be expected to alter ciliary signaling. A recent study suggests that the various GPCRs present in cilia physically interact with each other (Green et al., 2012). Because heteromerization of ciliary GPCRs has been proposed to increase the complexity of ciliary signaling, overexpression of specific receptors would cause an imbalance in the ratios of these receptors and may compromise ciliary signaling. Moreover, the forced exclusion of receptors, such as SSTR3 from the cilia of neurons overexpressing 5HT6, could contribute to learning and memory deficits as observed in SSTR3 knock-out mice (Einstein et al., 2010).

Normally, ACIII is trafficked into cilia during the earliest stages of neuronal ciliogenesis and persists throughout adulthood (Bishop et al., 2007; Arellano et al., 2012). We were unable to detect ACIII in the cilia of neurons overexpressing 5HT6:EGFP and did not detect an accumulation of ACIII around the bases of the elongated cilia or in the soma from these cells. Surprisingly, overexpression of SSTR3:EGFP, which lengthened neuronal cilia, was not accompanied by a loss of ciliary ACIII staining. In addition, the ciliary phenotype associated with overexpression of SSTR3:EGFP was not as severe as that observed in cells overexpressing 5HT6:EGFP. Together, these results suggest that the unique transport demands created by overexpression of 5HT6: EGFP reduced the trafficking of native ACIII, SSTR3, and perhaps other important signaling molecules into the cilium. The reduced levels of these molecules in these cilia would likely impair the ability of the cilia to detect and respond to cues in the local extracellular milieu.

\section{Cilia malformation, dendrite abnormalities, and ACIII}

We found that neocortical neurons overexpressing cilia GPCRs grow excessively long/malformed cilia and defective dendritic arbors. Intriguingly, the severity of the dendritic defect was positively correlated with the severity of the ciliary structural defect. The dendritic defects that we observed in our study were more severe than those reported in a recent study of the adult dentate gyrus. In that study, blocking the formation of cilia by expressing dnKif3a in neurons born in the adult dentate gyrus shortened the dendrites elaborated by these cells and delayed their arborization, but did not alter their complexity as assessed by Sholl analysis (Kumamoto et al., 2012). Although we did not measure the lengths of the dendrites elaborated by our cultured neocortical neurons expressing dnKif3a, we did find that overexpression of either dnKif3a or ciliary GPCRs in these cells reduced the complexity of the perisomal dendrites elaborated by these cells. The differences observed in the results of these two studies could indicate that different populations of neurons (in this case adult born dentate granule vs developing neocortical pyramidal neurons) respond differently to disruption of Kif3a function. It is noteworthy that overexpression of double-cortin domaincontaining protein 2, a molecule that interacts with KIF3A, has recently been reported to induce abnormal cilia growth in hippocampal neuron cultures and in ciliated Caenorhabditis elegans neurons that was associated with abnormal dendritic outgrowth (Massinen et al., 2011).

To what extent are ciliogenesis and dendrite formation in neocortical neurons linked? Our data suggest these two processes are interdependent. We observed that overexpression of 5HT6:EGFP induced abnormal growth of the cilia, significantly reduced cili- 
ary ACIII levels, and disrupted dendrite growth. We also found that overexpression of ACIII in these cells reversed these effects. Importantly, overexpression of ACIII and dnKif3a did not alter the dendritic defects exhibited by these cells. Together, these results suggest that ciliary ACIII is required for normal dendritogenesis. Whether ACIII itself directly regulates dendrite formation or functions in concert with other signaling molecules requires further study. Interestingly, a recent study of ACIIIdeficient mice shows that these mice exhibit deficits in learning and memory (Wang et al., 2011). Our results suggest these deficits may, in part, reflect defects in growth of neuronal dendrites. At this time, it is unclear whether the reduction in the lengths of the cilia produced by neurons coexpressing 5HT6:EGFP and ACIII:EGFP was the result of a reduction in the amount of 5HT6: EGFP trafficked into the cilia or restoration of ACIII signaling from the cilia.

In conclusion, our data and those of recent studies support a link between cilia and dendrite growth. We observed that disruption of ciliogenesis in layer $2 / 3$ cortical neurons, as well as in cells destined for the deeper layers of neocortex, reduced dendritogenesis, suggesting that the effects of cilia on cytoarchitecture are not limited to one neuronal cell type. It is possible that this effect does not generalize to all neocortical neuron subtypes. For example, a recent study of developing neocortical inhibitory interneurons shows that targeted ablation of the cilia of these cells induced aberrant migration of these cells and their final position in neocortex but did not dramatically alter their postmigratory differentiation (Higginbotham et al., 2012). Interestingly, these authors also found that targeted ablation of Arl13b in projection neurons did not alter their migration but did induce axonal outgrowth and connectivity defects. Together, these results suggest that the impact that ciliogenesis has on neuronal development and maturation may depend on the developmental age and subtype of the neuron. Unraveling these phenotypes may represent a key to understanding the various neurological symptoms exhibited by patients diagnosed with ciliopathies, including cognitive deficits, autism spectrum disorders, seizures, schizophrenia, and developmental dyslexia (Marley and von Zastrow, 2010; Lee and Gleeson, 2011; Louvi and Grove, 2011; Massinen et al., 2011). The specific changes induced in the neural network or in signaling pathways by cilia defects may depend on the nature of the defect and the type of neuron affected.

\section{References}

Anastas SB, Mueller D, Semple-Rowland SL, Breunig JJ, Sarkisian MR (2011) Failed cytokinesis of neural progenitors in citron kinase-deficient rats leads to multiciliated neurons. Cereb Cortex 21:338-344. CrossRef Medline

Arellano JI, Guadiana SM, Breunig JJ, Rakic P, Sarkisian MR (2012) Development and distribution of neuronal cilia in mouse neocortex. J Comp Neurol 520:848-873. CrossRef Medline

Avasthi P, Marshall WF (2012) Stages of ciliogenesis and regulation of ciliary length. Differentiation 83 [Suppl]:S30-S42.

Avasthi P, Marley A, Lin H, Gregori-Puigjane E, Shoichet BK, von Zastrow M, Marshall WF (2012) A chemical screen identifies class a G-protein coupled receptors as regulators of cilia. ACS Chem Biol 7:911-919. CrossRef Medline

Bennouna-Greene V, Kremer S, Stoetzel C, Christmann D, Schuster C, Durand M, Verloes A, Sigaudy S, Holder-Espinasse M, Godet J, Brandt C, Marion V, Danion A, Dietemann JL, Dollfus H (2011) Hippocampal dysgenesis and variable neuropsychiatric phenotypes in patients with Bardet-Biedl syndrome underline complex CNS impact of primary cilia. Clin Genet 80:523-531. CrossRef Medline

Berbari NF, Bishop GA, Askwith CC, Lewis JS, Mykytyn K (2007) Hippocampal neurons possess primary cilia in culture. J Neurosci Res 85 : 1095-1100. CrossRef Medline
Berbari NF, Johnson AD, Lewis JS, Askwith CC, Mykytyn K (2008a) Identification of ciliary localization sequences within the third intracellular loop of G protein-coupled receptors. Mol Biol Cell 19:1540-1547. CrossRef Medline

Berbari NF, Lewis JS, Bishop GA, Askwith CC, Mykytyn K (2008b) Bardet-Biedl syndrome proteins are required for the localization of $G$ protein-coupled receptors to primary cilia. Proc Natl Acad Sci U S A 105:4242-4246. CrossRef Medline

Bishop GA, Berbari NF, Lewis J, Mykytyn K (2007) Type III adenylyl cyclase localizes to primary cilia throughout the adult mouse brain. J Comp Neurol 505:562-571. CrossRef Medline

Brailov I, Bancila M, Brisorgueil MJ, Miquel MC, Hamon M, Vergé D (2000) Localization of 5-HT(6) receptors at the plasma membrane of neuronal cilia in the rat brain. Brain Res 872:271-275. CrossRef Medline

Breunig JJ, Sarkisian MR, Arellano JI, Morozov YM, Ayoub AE, Sojitra S, Wang B, Flavell RA, Rakic P, Town T (2008) Primary cilia regulate hippocampal neurogenesis by mediating sonic hedgehog signaling. Proc Natl Acad Sci U S A 105:13127-13132. CrossRef Medline

Chakravarthy B, Gaudet C, Ménard M, Atkinson T, Chiarini A, Dal Prà I, Whitfield J (2010) The p75 neurotrophin receptor is localized to primary cilia in adult murine hippocampal dentate gyrus granule cells. Biochem Biophys Res Commun 401:458-462. CrossRef Medline

Chizhikov VV, Davenport J, Zhang Q, Shih EK, Cabello OA, Fuchs JL, Yoder BK, Millen KJ (2007) Cilia proteins control cerebellar morphogenesis by promoting expansion of the granule progenitor pool. J Neurosci 27: 9780-9789. CrossRef Medline

Dave RH, Saengsawang W, Yu JZ, Donati R, Rasenick MM (2009) Heterotrimeric G-proteins interact directly with cytoskeletal components to modify microtubule-dependent cellular processes. Neurosignals 17:100 108. CrossRef Medline

Davé RH, Saengsawang W, Lopus M, Davé S, Wilson L, Rasenick MM (2011) A molecular and structural mechanism for G protein-mediated microtubule destabilization. J Biol Chem 286:4319-4328. CrossRef Medline

Davenport JR, Watts AJ, Roper VC, Croyle MJ, van Groen T, Wyss JM, Nagy TR, Kesterson RA, Yoder BK (2007) Disruption of intraflagellar transport in adult mice leads to obesity and slow-onset cystic kidney disease. Curr Biol 17:1586-1594. CrossRef Medline

Domire JS, Green JA, Lee KG, Johnson AD, Askwith CC, Mykytyn K (2011) Dopamine receptor 1 localizes to neuronal cilia in a dynamic process that requires the Bardet-Biedl syndrome proteins. Cell Mol Life Sci. 68:29512960. CrossRef Medline

Einstein EB, Patterson CA, Hon BJ, Regan KA, Reddi J, Melnikoff DE, Mateer MJ, Schulz S, Johnson BN, Tallent MK (2010) Somatostatin signaling in neuronal cilia is critical for object recognition memory. J Neurosci 30: 4306-4314. CrossRef Medline

Follit JA, Li L, Vucica Y, Pazour GJ (2010) The cytoplasmic tail of fibrocystin contains a ciliary targeting sequence. J Cell Biol 188:21-28. CrossRef Medline

Garcia-Gonzalo FR, Reiter JF (2012) Scoring a backstage pass: mechanisms of ciliogenesis and ciliary access. J Cell Biol 197:697-709. CrossRef Medline

Geng L, Okuhara D, Yu Z, Tian X, Cai Y, Shibazaki S, Somlo S (2006) Polycystin-2 traffics to cilia independently of polycystin-1 by using an N-terminal RVxP motif. J Cell Sci 119:1383-1395. CrossRef Medline

Goetz SC, Anderson KV (2010) The primary cilium: a signalling centre during vertebrate development. Nat Rev Genet 11:331-344. CrossRef Medline

Green JA, Mykytyn K (2010) Neuronal ciliary signaling in homeostasis and disease. Cell Mol Life Sci 67:3287-3297. CrossRef Medline

Green JA, Gu C, Mykytyn K (2012) Heteromerization of ciliary G proteincoupled receptors in the mouse brain. PLoS ONE 7:e46304. CrossRef Medline

Grissom PM, Vaisberg EA, McIntosh JR (2002) Identification of a novel light intermediate chain (D2LIC) for mammalian cytoplasmic dynein 2. Mol Biol Cell 13:817-829. CrossRef Medline

Hamon M, Doucet E, Lefevre K, Miquel MC, Lanfumey L, Insausti R, Frechilla D, Del Rio J, Verge D (1999) Antibodies and antisense oligonucleotide for probing the distribution and putative functions of central 5-HT6 receptors. Neuropsychopharmacology 21 [Suppl]:68S-76S.

Han YG, Spassky N, Romaguera-Ros M, Garcia-Verdugo JM, Aguilar A, Schneider-Maunoury S, Alvarez-Buylla A (2008) Hedgehog signaling 
and primary cilia are required for the formation of adult neural stem cells. Nat Neurosci 11:277-284. CrossRef Medline

Händel M, Schulz S, Stanarius A, Schreff M, Erdtmann-Vourliotis M, Schmidt H, Wolf G, Höllt V (1999) Selective targeting of somatostatin receptor 3 to neuronal cilia. Neuroscience 89:909-926. CrossRef Medline

Higginbotham H, Eom TY, Mariani LE, Bachleda A, Hirt J, Gukassyan V, Cusack CL, Lai C, Caspary T, Anton ES (2012) Arl13b in primary cilia regulates the migration and placement of interneurons in the developing cerebral cortex. Dev Cell 23:925-938.

Kang H, Lee WK, Choi YH, Vukoti KM, Bang WG, Yu YG (2005) Molecular analysis of the interaction between the intracellular loops of the human serotonin receptor type 6 (5-HT6) and the alpha subunit of GS protein. Biochem Biophys Res Commun 329:684-692. CrossRef Medline

Kozminski KG, Johnson KA, Forscher P, Rosenbaum JL (1993) A motility in the eukaryotic flagellum unrelated to flagellar beating. Proc Natl Acad Sci U S A 90:5519-5523. CrossRef Medline

Kumamoto N, Gu Y, Wang J, Janoschka S, Takemaru K, Levine J, Ge S (2012) A role for primary cilia in glutamatergic synaptic integration of adultborn neurons. Nat Neurosci 15:399-405. CrossRef Medline

Law SF, Zaina S, Sweet R, Yasuda K, Bell GI, Stadel J, Reisine T (1994) Gi $\alpha$ 1 selectively couples somatostatin receptor subtype 3 to adenylyl cyclase: identification of the functional domains of this $\alpha$ subunit necessary for mediating the inhibition by somatostatin of cAMP formation. Mol Pharmacol 45:587-590. Medline

Lee JE, Gleeson JG (2011) Cilia in the nervous system: linking cilia function and neurodevelopmental disorders. Curr Opin Neurol 24:98-105. CrossRef Medline

Louvi A, Grove EA (2011) Cilia in the CNS: the quiet organelle claims center stage. Neuron 69:1046-1060. CrossRef Medline

Makokha M, Hare M, Li M, Hays T, Barbar E (2002) Interactions of cytoplasmic dynein light chains Tctex-1 and LC8 with the intermediate chain IC74. Biochemistry 41:4302-4311. CrossRef Medline

Marley A, von Zastrow M (2010) DISC1 regulates primary cilia that display specific dopamine receptors. PLoS ONE 5:e10902. CrossRef Medline

Massinen S, Hokkanen ME, Matsson H, Tammimies K, Tapia-Páez I, Dahlström-Heuser V, Kuja-Panula J, Burghoorn J, Jeppsson KE, Swoboda P, Peyrard-Janvid M, Toftgård R, Castrén E, Kere J (2011) Increased expression of the dyslexia candidate gene DCDC2 affects length and signaling of primary cilia in neurons. PLoS ONE 6:e20580. CrossRef Medline

Miyoshi K, Onishi K, Asanuma M, Miyazaki I, Diaz-Corrales FJ, Ogawa N (2006) Embryonic expression of pericentrin suggests universal roles in ciliogenesis. Dev Genes Evol 216:537-542. CrossRef Medline

Miyoshi K, Kasahara K, Miyazaki I, Asanuma M (2011) Factors that influence primary cilium length. Acta Med Okayama 65:279-285. Medline

Mukhopadhyay S, Wen X, Chih B, Nelson CD, Lane WS, Scales SJ, Jackson PK (2010) TULP3 bridges the IFT-A complex and membrane phosphoinositides to promote trafficking of $\mathrm{G}$ protein-coupled receptors into primary cilia. Genes Dev 24:2180-2193. CrossRef Medline

Nachury MV, Loktev AV, Zhang Q, Westlake CJ, Peränen J, Merdes A, Slusarski DC, Scheller RH, Bazan JF, Sheffield VC, Jackson PK (2007) A core complex of BBS proteins cooperates with the GTPase Rab8 to promote ciliary membrane biogenesis. Cell 129:1201-1213. CrossRef Medline

Novarino G, Akizu N, Gleeson JG (2011) Modeling human disease in humans: the ciliopathies. Cell 147:70-79. CrossRef Medline

Ou Y, Ruan Y, Cheng M, Moser JJ, Rattner JB, van der Hoorn FA (2009) Adenylate cyclase regulates elongation of mammalian primary cilia. Exp Cell Res 315:2802-2817. CrossRef Medline
Pazour GJ, Wilkerson CG, Witman GB (1998) A dynein light chain is essential for the retrograde particle movement of intraflagellar transport (IFT). J Cell Biol 141:979-992. CrossRef Medline

Riccio O, Potter G, Walzer C, Vallet P, Szabó G, Vutskits L, Kiss JZ, Dayer AG (2009) Excess of serotonin affects embryonic interneuron migration through activation of the serotonin receptor 6. Mol Psychiatry 14:280-290. CrossRef Medline

Sarkisian MR, Siebzehnrubl D (2012) Abnormal levels of Gadd45 $\alpha$ in developing neocortex impair neurite outgrowth. PLoS ONE 7:e44207. CrossRef Medline

Sarkisian MR, Bartley CM, Chi H, Nakamura F, Hashimoto-Torii K, Torii M, Flavell RA, Rakic P (2006) MEKK4 signaling regulates filamin expression and neuronal migration. Neuron 52:789-801. CrossRef Medline

Satir P, Pedersen LB, Christensen ST (2010) The primary cilium at a glance. J Cell Sci 123:499-503. CrossRef Medline

Sattar S, Gleeson JG (2011) The ciliopathies in neuronal development: a clinical approach to investigation of Joubert syndrome and Joubert syndrome-related disorders. Dev Med Child Neurol 53:793-798. CrossRef Medline

Sharma N, Kosan ZA, Stallworth JE, Berbari NF, Yoder BK (2011) Soluble levels of cytosolic tubulin regulate ciliary length control. Mol Biol Cell 22:806-816. CrossRef Medline

Spassky N, Han YG, Aguilar A, Strehl L, Besse L, Laclef C, Ros MR, GarciaVerdugo JM, Alvarez-Buylla A (2008) Primary cilia are required for cerebellar development and Shh-dependent expansion of progenitor pool. Dev Biol 317:246-259. CrossRef Medline

Stanić D, Malmgren H, He H, Scott L, Aperia A, Hökfelt T (2009) Developmental changes in frequency of the ciliary somatostatin receptor 3 protein. Brain Res 1249:101-112. CrossRef Medline

Tai AW, Chuang JZ, Bode C, Wolfrum U, Sung CH (1999) Rhodopsin's carboxy-terminal cytoplasmic tail acts as a membrane receptor for cytoplasmic dynein by binding to the dynein light chain Tctex-1. Cell 97:877-887. CrossRef Medline

Taschner M, Bhogaraju S, Lorentzen E (2012) Architecture and function of IFT complex proteins in ciliogenesis. Differentiation 83 [Suppl]:S12-S22.

Verrier JD, Madorsky I, Coggin WE, Geesey M, Hochman M, Walling E, Daroszewski D, Eccles KS, Ludlow R, Semple-Rowland SL (2011) Bicistronic lentiviruses containing a viral $2 \mathrm{~A}$ cleavage sequence reliably coexpress two proteins and restore vision to an animal model of LCA1. PLoS One 6:e20553. CrossRef Medline

Wang Z, Phan T, Storm DR (2011) The type 3 adenylyl cyclase is required for novel object learning and extinction of contextual memory: role of cAMP signaling in primary cilia. J Neurosci 31:5557-5561. CrossRef Medline

Willaredt MA, Hasenpusch-Theil K, Gardner HA, Kitanovic I, HirschfeldWarneken VC, Gojak CP, Gorgas K, Bradford CL, Spatz J, Wölfl S, Theil $\mathrm{T}$, Tucker KL (2008) A crucial role for primary cilia in cortical morphogenesis. J Neurosci 28:12887-12900. CrossRef Medline

Yu JZ, Dave RH, Allen JA, Sarma T, Rasenick MM (2009) Cytosolic G $\alpha$ s acts as an intracellular messenger to increase microtubule dynamics and promote neurite outgrowth. J Biol Chem 284:10462-10472. CrossRef Medline

Zhang J, Shen CP, Xiao JC, Lanza TJ, Lin LS, Francis BE, Fong TM, Chen RZ (2006) Effects of mutations at conserved TM II residues on ligand binding and activation of mouse 5-HT6 receptor. Eur J Pharmacol 534:77-82. CrossRef Medline 